\title{
Joint retrievals of cloud and drizzle in marine boundary layer clouds using ground-based radar, lidar and zenith radiances
}

\author{
M. D. Fielding ${ }^{1}$, J. C. Chiu ${ }^{1}$, R. J. Hogan ${ }^{1}$, G. Feingold ${ }^{2}$, E. Eloranta ${ }^{3}$, E. J. O'Connor ${ }^{1,4}$, and M. P. Cadeddu ${ }^{5}$ \\ ${ }^{1}$ Department of Meteorology, University of Reading, Reading, UK \\ ${ }^{2}$ NOAA Earth System Research Laboratory, Boulder, Colorado, USA \\ ${ }^{3}$ Space Science and Engineering Center, University of Wisconsin, Madison, Wisconsin, USA \\ ${ }^{4}$ Finnish Meteorological Institute, Helsinki, Finland \\ ${ }^{5}$ Argonne National Laboratory, Argonne, Illinois, USA \\ Correspondence to: M. D. Fielding (m.d.fielding@pgr.reading.ac.uk)
}

Received: 30 December 2014 - Published in Atmos. Meas. Tech. Discuss.: 16 February 2015

Revised: 12 May 2015 - Accepted: 29 May 2015 - Published: 02 July 2015

\begin{abstract}
Active remote sensing of marine boundary-layer clouds is challenging as drizzle drops often dominate the observed radar reflectivity. We present a new method to simultaneously retrieve cloud and drizzle vertical profiles in drizzling boundary-layer clouds using surface-based observations of radar reflectivity, lidar attenuated backscatter, and zenith radiances under conditions when precipitation does not reach the surface. Specifically, the vertical structure of droplet size and water content of both cloud and drizzle is characterised throughout the cloud. An ensemble optimal estimation approach provides full error statistics given the uncertainty in the observations. To evaluate the new method, we first perform retrievals using synthetic measurements from large-eddy simulation snapshots of cumulus under stratocumulus, where cloud water path is retrieved with an error of $31 \mathrm{~g} \mathrm{~m}^{-2}$. The method also performs well in non-drizzling clouds where no assumption of the cloud profile is required. We then apply the method to observations of marine stratocumulus obtained during the Atmospheric Radiation Measurement MAGIC deployment in the Northeast Pacific. Here, retrieved cloud water path agrees well with independent threechannel microwave radiometer retrievals, with a root mean square difference of $10-20 \mathrm{~g} \mathrm{~m}^{-2}$.
\end{abstract}

\section{Introduction}

Marine boundary layer clouds typically contain two modes in their drop size distributions. The first, known as the "cloud mode", relates to droplets formed by condensational growth that rarely exceed $20 \mu \mathrm{m}$ radius (Devenish et al., 2012). Due to their relative abundance, these cloud droplets largely govern the radiative properties of the cloud. The second, known as the "drizzle mode", relates to drops formed by collisions and coalescence, typically with radius $25-200 \mu \mathrm{m}$. While the drizzle mode usually has a negligible direct effect on the cloud's radiative properties it does so indirectly through effects on cloud lifetime (e.g. Nicholls, 1984; Feingold et al., 1996) and evolution (Wood, 2006). In tandem with modelling studies, observations of how these processes interact are vital for accurate radiation and microphysical parameterisations in climate modelling and numerical weather prediction (e.g. Boutle et al., 2014).

While satellites provide an unrivalled global platform for the study of clouds, surface-based observations are vital for studying clouds at the process scale. For example, passive visible and infrared satellite observations, such as those from Moderate Resolution Imaging Spectroradiometer (MODIS), are suited to study the radiative properties of clouds, but using these measurements to quantify drizzle properties is much more difficult (e.g. Nakajima et al., 2010; Zhang et al., 2012). More recently, CloudSat (Stephens et al., 2002) has revealed the vertical structure of clouds (e.g. Lee et al., 2010) and the presence of drizzle from space (e.g. Leon et al., 2008; Lebsock et al., 2013), but often fails to observe the drizzle that occurs in the lowest $1 \mathrm{~km}$ of the atmosphere due to contamination from the strong surface return (Christensen et al., 2013). In addition, surface-based observations tend to 
have better resolution and sensitivity due to their proximity to their targets.

Numerous methods for retrieving cloud properties from surface-based sensors have been proposed; however, most are suitable only for non-drizzling clouds (e.g. Frisch et al., 1995, 1998; Dong and Mace, 2003) and assume a monomodal size distribution. Drizzling clouds pose a particular challenge to remote sensing as the larger droplets can dominate the radar reflectivity signal, which makes it hard to separate cloud and drizzle modes. One way to separate the modes is to exploit the differential fall speeds using Doppler spectra (Luke and Kollias, 2013). Additionally, dual-wavelength radar can retrieve liquid water content (LWC) profiles in drizzle (Hogan et al., 2005). In the drizzle beneath cloud base this ambiguity does not exist, so active remote sensing methods are well suited to retrieve drizzle properties. Existing retrieval methods for drizzle successfully exploit a combination of lidar and radar (O'Connor et al., 2005), or differences in backscatter at two different lidar wavelengths (Westbrook et al., 2010; Lolli et al., 2013), but cannot be extended above cloud base due to lidar attenuation and the breakdown of the single-mode assumption.

In this paper we develop a new method that allows the simultaneous retrieval of both cloud and drizzle modes using an optimal estimation framework. The drizzle mode is mainly constrained by active remote sensing observations from radar and lidar, while the cloud mode is constrained using passive remote sensing observations of zenith radiances (Chiu et al., 2012) to accommodate the two modes that occur within drizzling clouds. To combine the different observations, we extend the flexible Ensemble Cloud Retrieval (ENCORE) method previously applied to scanning radar measurements for providing 3-D non-drizzling cloud properties (Fielding et al., 2014). We test ENCORE using a combination of state-of-the-art large eddy simulations (LES) with size-resolved microphysics, and real ship-borne data from the recent Marine Atmospheric Radiation Measurement (ARM) GPCI Investigation of Clouds (MAGIC) campaign. By separating the cloud and drizzle modes we should gain further insight to processes within marine boundary layer clouds and provide new constraints for model development.

The paper is organised as follows. In Sect. 2 we describe the instrumentation and associated uncertainties for our observations. We outline the retrieval method in Sect. 3, before an evaluation using synthetic measurements from two cumulus-under-stratocumulus LES snapshots with contrasting drizzle rates in Sect. 4. Section 5 contains results from two case studies using real data from the MAGIC field campaign, including a comparison with other retrieval methods. A conclusion and summary is provided in Sect. 6.

\section{Observations}

\subsection{Measurements used in ENCORE}

The primary aim of the year-long MAGIC observational campaign was to improve our understanding of boundary layer clouds and their representation in climate models (Lewis and Teixeira, 2015). One particular region not well represented is the stratocumulus-to-cumulus transition zone in the eastern North Pacific (Teixeira et al., 2011). As a consequence, the poor representation of clouds in such regions contributes to the large uncertainty in modelled climate sensitivity to anthropogenic emissions. Although progress has been made to improve their representation, primarily through the comparison of single-column models and LES, a fundamental limitation to further progress is the lack of observational data. MAGIC has helped address this problem by collecting measurements from a suite of instruments deployed on a cargo ship travelling between Los Angeles and Hawaii between October 2012 and September 2013, thus sampling part of the eastern North Pacific stratocumulus-to-cumulus transition zone.

In this study we used active and passive remote sensing observations, namely the marine W-band ARM cloud radar (MWACR; Widener and Johnson, 2006), Ka-band ARM zenith cloud radar (KAZR; Widener et al., 2012), high spectral resolution lidar (HSRL) and a sun photometer (Holben et al., 1998). All measurements were averaged to a common $5 \mathrm{~s}$ resolution and $30 \mathrm{~m}$ height resolution to increase sensitivity and reduce errors from mismatching field-of-views (FOV). At a distance of $1 \mathrm{~km}$, the instantaneous footprint of each instrument is $\sim 10 \mathrm{~m}$ for the radars, $\sim 20 \mathrm{~m}$ for the sun photometer and $\sim 0.2 \mathrm{~m}$ for the HSRL. To correct the data for ship motion we use on-board accelerometers that can provide accurate information on the orientation of the ship at any given time.

Radar reflectivity factor is measured by the MWACR and KAZR. After averaging to the common resolution, the sensitivity of MWACR and KAZR is about -50 and $-45 \mathrm{dBZ}$ at $1 \mathrm{~km}$, respectively. Attenuation of radar beams due to water vapour and liquid water are accounted for in our retrieval method. Similar to Rémillard et al. (2013), water vapour attenuation is approximated by distributing the total column water vapour retrievals from microwave radiometer (MWR) measurements as an exponential function of height (Matrosov et al., 2004). Alternatively, total gaseous attenuation at each radar frequency can be calculated from the vertical profiles of temperature, pressure and humidity from a radiosonde, or from a numerical forecast model (Illingworth et al., 2007) using the line-by-line model of Liebe (1985). The vertical profile of attenuation can also be approximated. In contrast, liquid water attenuation is included in the retrieval process explicitly and discussed in more detail in Sect. 3.3.1.

Attenuated backscatter $\left(\beta^{\prime}\right)$ is measured using the HSRL. The HSRL operates at $532 \mathrm{~nm}$ with a FOV of $0.1 \mathrm{mrad}$ (see 


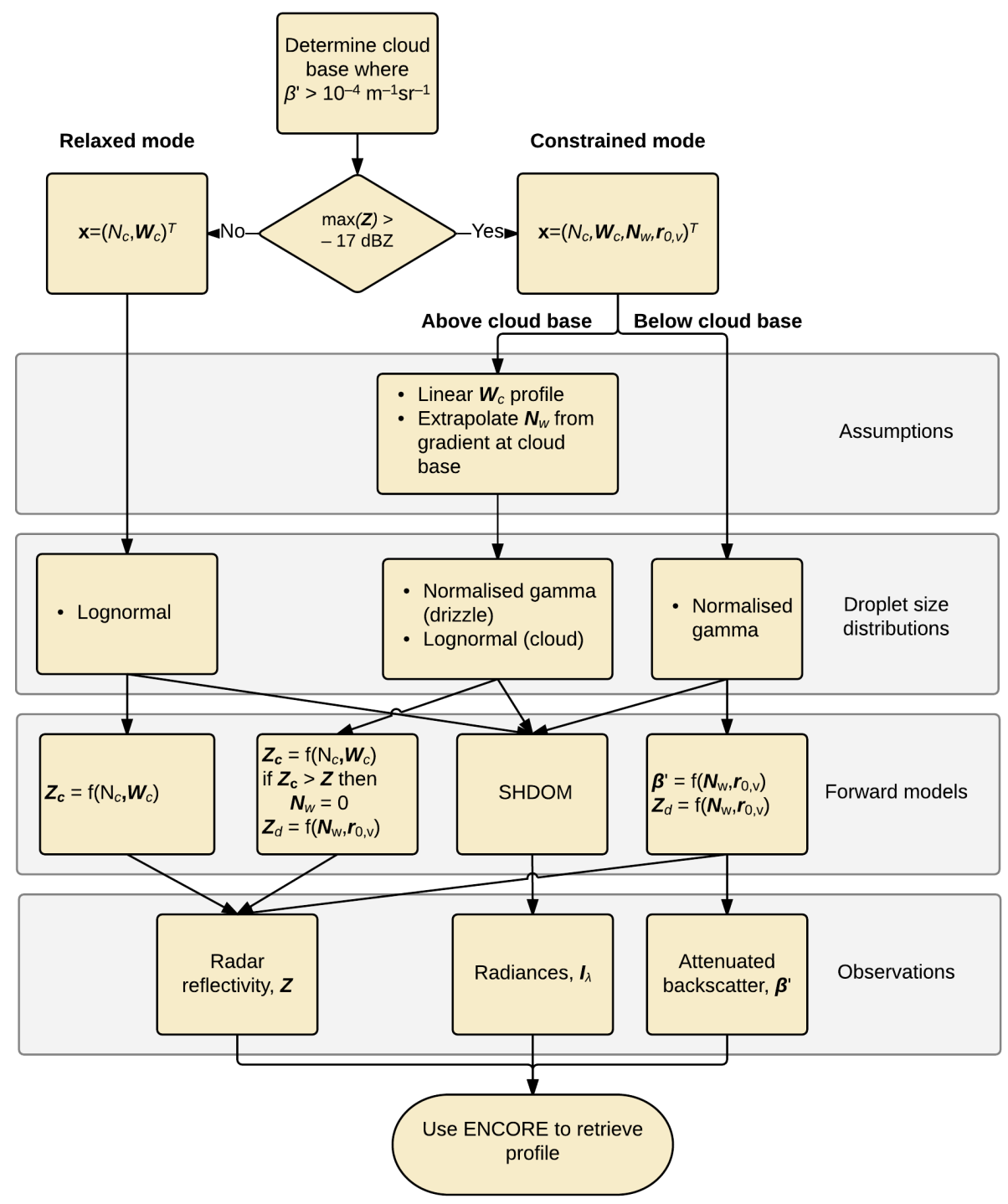

Figure 1. Schematic showing the retrieval, see Fielding et al. (2014) for ENCORE schematic.

Table 1). The attenuated backscatter is normalised to the measured particle and known Rayleigh backscatter at a close range using the ability of the HSRL to separate molecular and particle returns (described later).

Compared to the relative large FOVs of most passive radiometers, the $1.2^{\circ}$ narrow FOV of the sun photometer is more suitable to observe the fine structure of clouds and better matches the FOVs of radar and lidar. The sun photometer deployed in the MAGIC campaign was modified to operate continuously in "cloud mode"; in other words, the sun photometer was pointed to vertical and measured zenith radiances at multiple wavelengths in the visible and nearinfrared. Specifically, we used measurements at 440,870 and $1640 \mathrm{~nm}$ that have previously been used to estimate cloud optical depth, liquid water path (LWP) and column-mean effective radius by Chiu et al. (2012), using a method that exploits differences in scattering and absorption between the wave- lengths. As the underlying retrieval principle relies on solar transmission and scattering, our retrievals are limited to daytime with solar zenith angle (SZA) smaller than $80^{\circ}$ when the solar signal is sufficient.

\subsection{Independent retrievals for evaluating ENCORE}

The observational data sets for evaluation include independent LWP retrievals from a three-channel microwave radiometer and drizzle properties below cloud base mainly from the HSRL. LWP retrievals were made using brightness temperatures at $23.8,30$ and $89 \mathrm{GHz}$ with a $10 \mathrm{~s}$ temporal resolution. A detailed description of the instrument and calibration can be found in Cadeddu et al. (2013). Compared to widely used two-channel radiometers, the additional frequency at $89 \mathrm{GHz}$ provides enhanced sensitivity to liquid water and thus helps reduce the retrieval uncertainty with re- 
Table 1. High spectral resolution lidar specifications.

\begin{tabular}{lr}
\hline Parameter & \\
\hline Transmitter & \\
\hline Wavelength (nm) & 532 \\
Average power (W) & 0.3 \\
Pulse width (ns) & 50 \\
Repetition frequency (kHz) & 4 \\
Bandwidth (MHz) & $<50$ \\
\hline Receiver & 0.4 \\
\hline Diameter (m) & 8 \\
Sky noise filter bandwidth (GHz) & $\mathrm{I} 2$ cell \\
Aerosol rejection filter & 7.5 \\
Range resolution (m) & 0.5 \\
Minimum integration time (s) & $\sim 60 \%$ \\
Geiger-mode APD detectors $(\mathrm{QE} *)$ & \\
\hline * Quantum efficiency. &
\end{tabular}

spect to two-channel retrievals. The three-channel retrieval method is an optimal estimation retrieval that uses information on the vertical profiles of temperature and humidity from a close radiosonde launch (launched every 6 hours from the ship), cloud base height from the ceilometer and an "a priori" estimate of the cloud profile. Starting from an initial first guess, radiative transfer computations are repeated and the cloud profile altered until a convergence is achieved between the modelled and observed brightness temperature. Because of the high information content of the measurements, the final retrievals are typically independent of the a priori used. The overall retrieval uncertainty is about $5-8 \mathrm{~g} \mathrm{~m}^{-2}$.

Another independent set of drizzle retrievals for evaluation uses the particle backscatter signal derived from HSRL observations and radar reflectivity from KAZR. While the retrieval follows the same basic approach of ENCORE, the retrieval is deterministic and a useful sanity check. The lidar extinction cross-section can be measured directly from the attenuation of the molecular return observed by the HSRL. However, for the cases shown in this study, the extinction cross-section is estimated from the lidar backscatter crosssection using an average lidar ratio of 15.4. The backscatter cross-section measurement is less sensitive to errors caused by multiple scattering, signal noise and lidar overlap corrections. Effective radius and liquid water content are derived from the ratio of radar backscatter cross-section to lidar extinction cross-section assuming a gamma distribution of particle sizes (Donovan and Lammeren, 2001). The dispersion parameters in the assumed gamma size distribution are adjusted to provide the best comparison of the time-averaged radar measured fall velocities with fall velocities computed from the size distribution.

Finally a radiance-only retrieval of cloud optical depth is performed using look-up tables created with radiative trans- fer calculations based on a single-mode size distribution. A detailed description of the method can be found in Chiu et al. (2012).

\section{Retrieval method}

To combine measurements of radar reflectivity, lidar attenuated backscatter and zenith radiance for cloud and drizzle retrievals in an optimal way, we use an adapted 1-D version of the 3-D ENCORE proposed by Fielding et al. (2014). One of the main advantages of ENCORE is its flexibility, allowing the retrieval to be switched between 1-D and 3-D versions, and to add or exclude individual instruments depending on their availability. While Fielding et al. (2014) concentrated on a 3-D framework for non-drizzling clouds using radar reflectivity and zenith radiance, this section reports on a 1D framework and extends its application to drizzling clouds by including lidar measurements. A schematic is provided in Fig. 1. The capability to retrieve drizzle in 1-D will provide the foundations for future retrievals of drizzling clouds in 3-D.

Our retrieval method includes three components. The first component is the state vector that describes the variables that we wish to retrieve. Second, forward models are needed to relate the state vector to our observations. Finally, we require a method to bring together the state and forward models with any assumptions, prior knowledge or constraints on the state. In this section, we briefly introduce the assumptions made, followed by descriptions of the state vector and the forward models, before outlining the procedure to find the best estimate of the state vector.

\subsection{Assumptions in particle size and vertical profile}

For each 1-D column, we classify the cloud as either nondrizzling or drizzling using a threshold of $-17 \mathrm{dBZ}$ in radar reflectivity. Where the maximum observed reflectivity within a column exceeds the threshold, we classify the cloud as drizzling. Using similar thresholds for delineating non-drizzling and drizzling clouds has been shown to hold empirically (e.g. Frisch et al., 1995; Wang and Geerts, 2003; Comstock et al., 2004; vanZanten et al., 2005) and theoretically (Liu et al., 2008). Such a classification is necessary in our retrieval method because the contribution of clouds to radar reflectivity can be obscured by drizzle drops and thus certain assumptions in the vertical profile of the cloud need to be made in drizzling cases. As a result, for drizzling cases, we assume a simple model for the condensational growth of cloud droplets in a cloud (e.g. Squires, 1952; Twomey, 1959), where all cloud droplets are activated at cloud base before growing by condensation through the depth of the cloud. This allows us to assume a constant cloud droplet number concentration $\left(N_{\mathrm{c}}\right)$ and a profile of liquid water content $\left(W_{\mathrm{c}}\right)$ that increases linearly, although not necessarily adiabatically with height. For non-drizzling clouds, no particular assumptions in the 
cloud profile are made, maximising the use of radar reflectivity to constrain cloud droplet size (similar to Fielding et al., 2014). For convenience, we hereafter refer to the retrieval methods with and without particular assumption in the cloud profile as "constrained mode" and "relaxed mode" respectively.

For cloud droplets, following Frisch et al. (1995) we assume a lognormal drop size distribution (DSD) given as

$n_{\mathrm{c}}(r)=\frac{N_{\mathrm{c}}}{\sqrt{2 \pi} \sigma r} \exp \left(\frac{-\left(\ln r-\ln r_{0}\right)^{2}}{2 \sigma^{2}}\right)$,

where $n_{\mathrm{c}}$ is the number concentration at a given cloud droplet radius $r$; the $r_{0}$ is the median radius and $\sigma$ is the geometric standard deviation. From Eq. (1), we can then compute the cloud effective radius $r_{\mathrm{e}, \mathrm{c}}$ and cloud water content $W_{\mathrm{c}}$ by

$r_{\mathrm{e}, \mathrm{c}}=r_{0} \exp \left(\frac{5}{2} \sigma^{2}\right)$

and

$W_{\mathrm{c}}=\frac{4 \pi \rho_{\mathrm{w}}}{3} N_{\mathrm{c}} r_{\mathrm{e}, \mathrm{c}}^{3} \exp \left(-3 \sigma^{2}\right)$,

where $\rho_{\mathrm{w}}$ is the density of water.

Similarly, we assume a normalised Gamma DSD for drizzle drops (Ulbrich, 1983):

$n_{\mathrm{d}}(r)=N_{\mathrm{w}} f(\mu)\left(\frac{r}{r_{0, \mathrm{v}}}\right)^{\mu} \exp \left(\frac{-[3.67+\mu] r}{r_{0, \mathrm{v}}}\right)$,

where $n_{\mathrm{d}}$ is the number concentration at a given drizzle drop radius $r$, the $r_{0, \mathrm{v}}$ is the median equivolumetric radius, $\mu$ is the shape parameter, $N_{\mathrm{w}}$ is the normalised drizzle drop number concentration so that the drizzle water content is independent of $\mu$, and finally

$f(\mu)=\frac{6}{3.67^{4}} \frac{(3.67+\mu)^{\mu+4}}{\Gamma(\mu+4)}$.

From Eq. (4) we can then compute the drizzle effective radius $r_{\mathrm{e}, \mathrm{d}}$ and drizzle water content $W_{\mathrm{d}}$ by

$r_{\mathrm{e}, \mathrm{d}}=\frac{\int_{0}^{\infty} n_{\mathrm{d}}(r) r^{3} d r}{\int_{0}^{\infty} n_{\mathrm{d}}(r) r^{2} d r}=\frac{(3+\mu)}{(3.67+\mu)} r_{0, \mathrm{v}}$,

$W_{\mathrm{d}}=\frac{4 \pi}{3} \rho_{w} \int_{0}^{\infty} n_{\mathrm{d}}(r) r^{3} d r=\frac{8 \pi}{3.67^{4}} \rho_{w} N_{\mathrm{w}} r_{0, \mathrm{v}}^{4}$.

As in situ measurements of $\mu$ (e.g. Ichimura et al., 1980; Wood, 2000) and $\sigma$ (e.g. Miles et al., 2000) are generally found to be within a small range of values - we assume $\mu=2$ and $\sigma=0.3$ in this study. Retrieved values of $r_{\mathrm{e}, \mathrm{d}}$ and $W_{\mathrm{d}}$ vary by less than $10 \%$ for $\mu=2 \pm 2$. Similarly, Fielding et al. (2014) found retrieved values of $r_{\mathrm{e}, \mathrm{c}}$ and $W_{\mathrm{c}}$ to vary by less than $10 \%$ for $\sigma=0.3 \pm 0.1$.

\subsection{State vector}

The state vector that we wish to retrieve, $\boldsymbol{x}$, is defined as

$\boldsymbol{x}=\log _{10}\left(N_{\mathrm{c}}, W_{\mathrm{c}}^{k=k_{\mathrm{cb}}, \ldots, k_{\mathrm{ct}}}\right)^{T}$ in relaxed mode,

$\boldsymbol{x}=\log _{10}\left(N_{\mathrm{c}}, W_{\mathrm{c}}^{k=k_{\mathrm{cb}}, \ldots, k_{\mathrm{ct}}}, N_{\mathrm{w}}^{k=k_{\mathrm{db}}, \ldots, k_{\mathrm{ct}}}, r_{0, \mathrm{v}}^{k=k_{\mathrm{db}}, \ldots, k_{\mathrm{ct}}}\right)^{T}$

in constrained mode,

where $N_{\mathrm{c}}$ is the height-independent cloud droplet number concentration, and $W_{\mathrm{c}}^{k}$ is the cloud liquid water content at a given layer $k$ from the cloud base $\left(k=k_{\mathrm{cb}}\right)$ to the cloud top $\left(k=k_{\mathrm{ct}}\right)$. Cloud base height can be determined using sophisticated existing algorithms that rely on the magnitude or gradient of lidar attenuated backscatter (e.g. Platt et al., 1994; Clothiaux et al., 1998). For simplicity, we determine cloud base using a threshold in attenuated lidar backscatter of $0.0001 \mathrm{~m}^{-1} \mathrm{sr}^{-1}$ (similar to O'Connor et al., 2004) in both cloud types. Cloud top is determined from the last radar range gate with a detectable signal, as in the Cloudnet target classification (Illingworth et al., 2007). Note that we specify the state vector with the variables in log space, forcing their values to be positive to avoid unphysical negative retrievals.

In constrained mode, we extend the state vector to include two drizzle variables as shown in Eq. (9), $N_{\mathrm{w}}$ and $r_{0, \mathrm{v}}$, which are retrieved from drizzle base $\left(k=k_{\mathrm{db}}\right)$ to the cloud top $\left(k=k_{\mathrm{ct}}\right)$. Similar to cloud top determination, drizzle base is determined from the first radar range gate with a detectable signal. Finally, we assume that $N_{\mathrm{w}}$ increases with height within the cloud with the same gradient as at cloud base based on in situ measurements reported by Wood (2005). To reduce noise in the retrieval, the mean gradient of the last four gates below cloud base is used in the extrapolation. If the gradient of $N_{\mathrm{w}}$ is negative at cloud base then $N_{\mathrm{w}}$ is assumed to be constant within cloud to prevent unphysical retrievals.

\subsection{Forward models}

To find the best estimate of $\boldsymbol{x}$, forward models are required to return the predicted observations for given values of $\boldsymbol{x}$. For both retrieval modes, we forward model observations of radar reflectivity and zenith radiances. Additionally, we forward model observations of lidar attenuated backscatter only in the precipitation falling below drizzling clouds, as the lidar signal tends to strongly attenuate in the cloud itself.

\subsubsection{Radar reflectivity}

Assuming Rayleigh scattering, the radar reflectivity due to cloud droplets, $Z_{\mathrm{c}}$, at each level $k$ can be written as

$$
Z_{\mathrm{c}}=2^{6} \int_{0}^{\infty} n_{\mathrm{d}}(r) r^{6} \mathrm{~d} r=\frac{36}{\pi^{2} \rho_{w}^{2}} \frac{W_{c}^{2}}{N_{\mathrm{c}}} \exp \left(9 \sigma^{2}\right) \text {. }
$$

For simplicity, in this and the following equations, we have omitted the variables' dependence on height. We also 
account for the variation of the dielectric constant, which changes with radar frequency and temperature. When the drizzle drop radius approaches the radar wavelength (around $150 \mu \mathrm{m}$ at $94 \mathrm{GHz}$ ), the Rayleigh scattering approximation is no longer valid. To correct for this we include a Mie-toRayleigh ratio, $\gamma^{*}$, in the drizzle reflectivity forward model. The Mie-to-Rayleigh ratio is calculated from Mie scattering theory using the drizzle DSD, and is therefore a function of $r_{0, \mathrm{v}}$ and $\mu$. Therefore, below cloud base, the radar reflectivity due to drizzle drops, $Z_{\mathrm{d}}$, at each level $k$ can be computed by

$$
\begin{aligned}
Z_{\mathrm{d}} & =2^{6} \gamma^{*}\left(r_{0, \mathrm{v}}, \mu\right) \int_{0}^{\infty} n(r) r^{6} \mathrm{~d} r \\
& =2^{6} N_{\mathrm{w}} \gamma\left(r_{0, \mathrm{v}}, \mu\right) \frac{\Gamma(7+\mu)}{(3.67+\mu)^{7+\mu}} f(\mu) r_{0, \mathrm{v}}^{7} \quad \text { for } k<k_{\mathrm{cb}}
\end{aligned}
$$

Between cloud base and drizzle top, the forward model for reflectivity needs to account for both cloud and drizzle. Since the cloud contribution to the radar reflectivity is $Z_{\mathrm{c}}$ in Eq. (10), we can estimate drizzle contribution to the radar reflectivity by

$Z_{\mathrm{d}}=\max \left(0, Z_{\text {obs }}-Z_{\mathrm{c}}\right)$

for layers between cloud base and cloud top,

where $Z_{\mathrm{obs}}$ is the observed reflectivity, and the maximum function ensures that the drizzle reflectivity $Z_{\mathrm{d}}$ is positive and valid. Drizzle is therefore not retrieved where the observed radar reflectivity is less than or equal to the forwardmodelled $Z_{\mathrm{c}}$.

Combining Eq. (10) with Eqs. (11) and (12), we can then forward model radar reflectivity using

$10 \log _{10} Z=10 \log _{10} Z_{\mathrm{c}}-2 \int_{0}^{L}\left(\kappa_{1} W_{\mathrm{c}}\right) \mathrm{d} L^{\prime}$,

in relaxed mode,

$10 \log _{10} Z=10 \log _{10}\left(Z_{\mathrm{c}}+Z_{\mathrm{d}}\right)-2 \int_{0}^{L}\left(\kappa_{1} W_{\mathrm{c}}+\kappa_{l} W_{\mathrm{d}}\right) \mathrm{d} L^{\prime}$

in constrained mode,

where $\kappa_{1}\left(\mathrm{~dB} \mathrm{~km}^{-1}\left(\mathrm{~g} \mathrm{~m}^{-3}\right)^{-1}\right)$ is the one-way specific attenuation coefficient of liquid water and $L$ is the distance to the radar. The observations are corrected for attenuation due to atmospheric gases beforehand as described in Sect. 2, so this attenuation does not need to be forward modelled.

\subsubsection{Lidar attenuated backscatter}

To forward model the lidar observations, we calculate the extinction coefficient, $\alpha$, from the state variables as

$$
\begin{aligned}
\alpha & =2 \pi \int_{0}^{\infty} n_{\mathrm{d}}(r) r^{2} \mathrm{~d} r \\
& =2 \pi N_{\mathrm{w}} \frac{\Gamma(3+\mu)}{(3.67+\mu)^{3+\mu}} f(\mu) r_{0, \mathrm{v}}^{3},
\end{aligned}
$$

where we have assumed the drizzle drops are much larger than the lidar wavelength. The lidar attenuated backscatter coefficient, $\beta^{\prime}$, due to drizzle drops is then given as

$\beta^{\prime}(L)=\frac{\alpha(L)}{S(L)} \exp \left(-2 \int_{0}^{L} \alpha\left(L^{\prime}\right) \mathrm{d} L^{\prime}\right)$,

where $S$ is the extinction-to-backscatter ratio that varies with wavelength and drop size, and $L$ is the distance to the lidar. A look-up table for $S$ is computed using Mie-theory code. Recall that the attenuated backscatter is only forward modelled below cloud base.

\subsubsection{Shortwave zenith radiance}

Zenith radiances, $I_{\lambda}$, are forward modelled using input profiles of $W_{\mathrm{c}}$ and $r_{\mathrm{e}, \mathrm{c}}$ and a 1-D radiative transfer model. The profile of $W_{\mathrm{c}}$ is obtained directly from the state vector (i.e. Eqs. 8 and 9), and the profile of $r_{\mathrm{e}}$ is computed from of $W_{\mathrm{c}}$ and $N_{\mathrm{c}}$ through Eq. (2). In constrained mode, an additional input profile is generated using $W_{\mathrm{d}}$ and $r_{\mathrm{e}, \mathrm{d}}$ calculated using Eqs. (5) and (6) respectively. The input property profiles are then used to determine the extinction, single-scattering albedo and phase function at each height level. Radiative transfer is computed using the Spherical Harmonics Discrete Ordinates Method (SHDOM; Evans, 1998) in 1-D mode. The surface albedo is specified using the ocean reflectance model included in the 2003 SHDOM distribution.

\subsection{Finding the best estimate of the state}

As proposed by Iglesias et al. (2013) and similar to Grecu and Olson (2008), we use an adaption to the ensemble Kalman filter for finding the best estimate of our state vector given the observations. The key steps of the method are summarised in this section; full details can be found in Fielding et al. (2014).

First, we define an ensemble $\mathbf{X}$ of individual state vectors, $\boldsymbol{x}$, containing $N$ members, i.e.

$\mathbf{X}=\left(\boldsymbol{x}_{1}, \ldots, \boldsymbol{x}_{N}\right)$,

where the subscript refers to the particular ensemble member. We use the mean of the ensemble to represent the best estimate of the state vector and the spread of the ensemble as the uncertainty. For each set of observations, $\boldsymbol{y}$, we apply the 
Table 2. Synthetic measurement values, initial guesses and their associated uncertainties for the LES experiments.

\begin{tabular}{|c|c|c|}
\hline Observation/parameter & Value & Uncertainty (1 SD) \\
\hline Radar reflectivity factor $(\mathrm{dBZ})^{*}$ & Computed from LES output & $1 \mathrm{~dB}$ \\
\hline Lidar attenuated backscatter $\left(\mathrm{sr}^{-1} \mathrm{~m}^{-1}\right)^{*}$ & Computed from LES output & $\sim 30 \%$ \\
\hline Zenith radiance $\left(\mathrm{W} \mathrm{m}^{-2} \mu \mathrm{m}^{-1} \mathrm{sr}^{-1}\right)^{*}$ & Computed from LES output & $2.5 \%$ \\
\hline \multicolumn{3}{|l|}{ Surface albedo } \\
\hline $440 \mathrm{~nm}$ & 0.05 & $10 \%$ \\
\hline $870 \mathrm{~nm}$ & 0.3 & $5 \%$ \\
\hline $1640 \mathrm{~nm}$ & 0.25 & $5 \%$ \\
\hline \multicolumn{3}{|l|}{ Cloud } \\
\hline $\begin{array}{l}\text { Logarithmic cloud droplet number } \\
\text { concentration }\left(N_{\mathrm{c}} ; \mathrm{cm}^{-3}\right)\end{array}$ & $\log _{10} 50$ & 1 \\
\hline $\begin{array}{l}\text { Logarithmic cloud liquid water } \\
\text { content }\left(W_{\mathrm{c}} ; \mathrm{g} \mathrm{m}^{-3}\right)\end{array}$ & $\begin{array}{l}\log _{10} 0.5 \text { at cloud top (scaled } \\
\text { linearly in linear space to } \\
\log _{10} 0.01 \text { at cloud base) }\end{array}$ & 1 \\
\hline \multicolumn{3}{|l|}{ Drizzle } \\
\hline $\begin{array}{l}\text { Logarithmic drizzle normalised } \\
\text { number concentration }\left(N_{\mathrm{w}} ; \mathrm{mm}^{-4}\right)\end{array}$ & $\log _{10} 10^{-3}$ & 2 \\
\hline $\begin{array}{l}\text { Logarithmic drizzle } \\
\text { equivolumetric radius }\left(r_{0, \mathrm{v}} ; \mathrm{mm}\right)\end{array}$ & $\log _{10} 0.025$ & 2 \\
\hline
\end{tabular}

* Assuming a $5 \mathrm{~s}$ sampling period.

extended Kalman filter update equations iteratively on each ensemble member $q$, i.e. for each iteration, $i$,

$\boldsymbol{x}_{q}^{i+1}=\boldsymbol{x}_{q}^{i}+\mathbf{P C}^{T}\left(\mathbf{C P C} \mathbf{C}^{T}+\mathbf{R}\right)^{-1}\left(\hat{\boldsymbol{y}}_{q}^{i}-h\left(\boldsymbol{x}_{q}^{i}\right)\right)$,

where the function $h(\boldsymbol{x})$ is the forward model; $\mathbf{C}$ is the Jacobian matrix of the forward model; $\mathbf{P}$ is the error covariance matrix of the current state; $\mathbf{R}$ is the observation error covariance matrix; and $\hat{\boldsymbol{y}}$ are the observations perturbed with random noise as specified in $\mathbf{R}$. We further use the ensemble to approximate $\mathbf{P C}^{T}$ and $\mathbf{C P C} \mathbf{C}^{T}$ by

$\mathbf{P C}^{T}=\frac{1}{N-1} \mathbf{E}_{x} \mathbf{E}_{y}^{T}$ and

$\mathbf{C P C}^{T}=\frac{1}{N-1} \mathbf{E}_{y} \mathbf{E}_{y}^{T}$,

where

$\mathbf{E}_{x}=\left[\boldsymbol{x}_{1}-\overline{\mathbf{X}}, \ldots, \boldsymbol{x}_{N}-\overline{\mathbf{X}}\right]$ and

$\mathbf{E}_{y}=\left[h\left(\boldsymbol{x}_{1}\right)-\bar{h}(\mathbf{X}), \ldots, h\left(\boldsymbol{x}_{N}\right)-\bar{h}(\mathbf{X})\right]$.

In Eqs. (21) and (22), $\mathbf{E}_{x}$ and $\mathbf{E}_{y}$ represent the ensemble spread and the spread in predicted observations values, respectively; $\bar{h}(\mathbf{X})$ is the mean of the forward modelled observations. Using this ensemble method avoids the need for the tangent linear or adjoint of the forward model. While such adjoints are available for 1-D radiative transfer, we use this ensemble method so that the retrieval can be easily extended to 3-D radiative transfer in the future; adjoints for 3-D radiative transfer are currently unavailable, although this is an active area of research (e.g. Martin et al., 2014).

For all the experiments in this paper, the initial ensemble is generated using random noise with large variance so that the ensemble spans a set of reasonable values (e.g. $N_{\mathrm{c}}=5-$ $500 \mathrm{~cm}^{-3}$, see Table 2), with a climatological or reasonable mean value (e.g. $N_{\mathrm{c}}=50 \mathrm{~cm}^{-3}$ ). Equation (18) is then iterated until a convergence criterion is met, or the number of iterations exceeds a predetermined threshold. The convergence criterion is set such that the difference between the ensemble mean of the forward-modelled observations and the observations is less than the observation uncertainty. The solution usually converges within five iterations. We have found that the initial guess has little influence on the final best estimate, but can affect the number of iterations before convergence.

\section{Evaluation using synthetic measurements from large eddy simulations}

We evaluate the retrieval method using snapshots of cumulus beneath stratocumulus, generated by an LES with idealised forcing data collected during the Atlantic Tradewind Experiment (ATEX). The ATEX data have also been widely analysed and modelled (e.g. Stevens and Lenschow, 2001). Details of the LES are provided in (Xue et al., 2008). The simulations are chosen as they contain a wide range of complex non-precipitating and precipitating clouds. Importantly, 

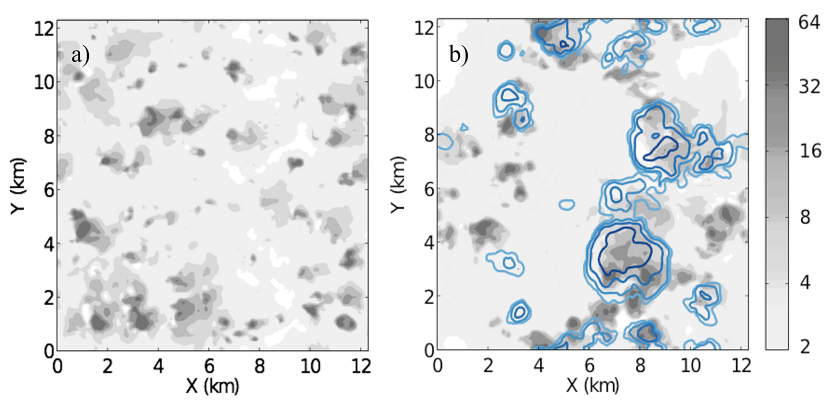

Figure 2. Cloud optical depth with contours of surface rain rate for (a) polluted case, (b) clean case. Surface rain rate contours represent $0.01,0.1,1,10 \mathrm{~mm} \mathrm{day}^{-1}$ from light blue to dark blue respectively.

the simulations use a size-resolving microphysical scheme; therefore, moments of the droplet size distribution such as $Z$, optical depth $(\tau)$, and effective radii of cloud droplets and drizzle drops can be calculated without assuming any particular particle size distribution.

The LES has a domain size of $12.4 \times 12.4 \times 3 \mathrm{~km}$ with grid spacing $100 \times 100 \times 20 \mathrm{~m}$. Two particular cases (Xue et al., 2008) with aerosol concentrations of $25 \mathrm{mg}^{-1}$ (“clean") and $100 \mathrm{mg}^{-1}$ ("polluted") are used, in an attempt to cover the diverse joint spatial distributions of cloud and drizzle. As shown in Fig. 2, the cloud field in the polluted case is mainly non-drizzling, while in the clean case surface rain rate as high as $10 \mathrm{~mm} \mathrm{day}^{-1}$ is evident. Since we retrieve properties for both cloud droplets and drizzle drops in the clean case, it is crucial to define what is cloud and drizzle more precisely. Here, we separate cloud and drizzle using a radius threshold of $40 \mu \mathrm{m}$. In other words, the "truth" cloud properties from the LES were calculated from the droplet size bins with radii smaller than the threshold, while the truth drizzle properties from the LES were calculated using the remaining size bins. The choice of the threshold is somewhat arbitrary, but cloud droplets grown by condensation alone rarely exceed $20 \mu \mathrm{m}$ radius, so any droplets with radii larger than $40 \mu \mathrm{m}$ must have experienced significant coalescence (Devenish et al., 2012). Note that this threshold is not known by the retrieval and only affects the truth cloud and drizzle properties.

Based on these simulations, synthetic observations of radar reflectivity, lidar attenuated backscatter and zenith radiances can be obtained using the forward models as mentioned in Sect. 3.3. Specifically, since the size distribution is explicitly simulated in the LES, the observed radar reflectivity can be computed directly from Eqs. (10) and (11). Similarly, the lidar attenuated backscatter is computed from Eqs. (15) and (16). The observed zenith radiances are computed with an assumed solar zenith angle (SZA) of $45^{\circ}$. Using Table 2, we then specify and add random Gaussian measurement uncertainty in log space to all computed values to obtain the final synthetic observations used for the evaluation.

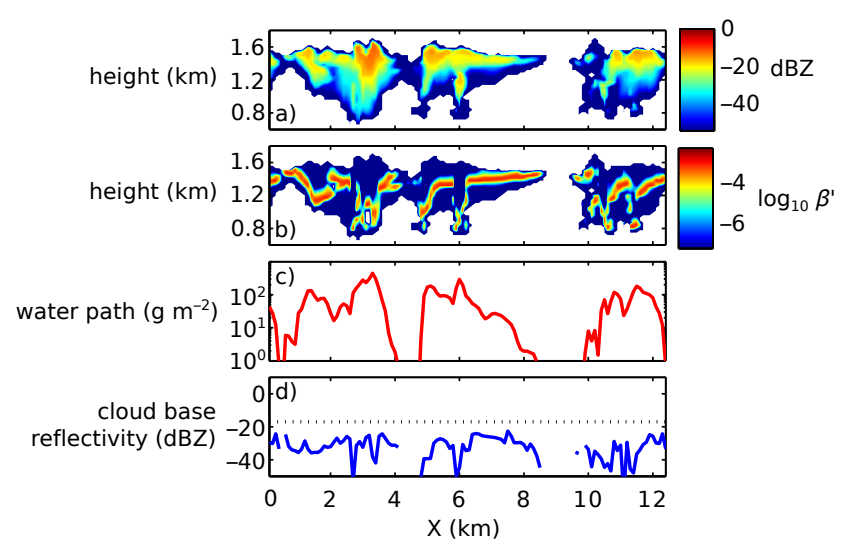

Figure 3. Synthetic observations for the polluted case along the cross-section $Y=2 \mathrm{~km}$ shown in Fig. 2a. From top: (a) total radar reflectivity $(\mathrm{dBZ})$; (b) lidar attenuated backscatter $\left[\log _{10}\right.$ $\left.\left(\mathrm{m}^{-1} \mathrm{sr}^{-1}\right)\right]$; (c) cloud water path $\left(\mathrm{g} \mathrm{m}^{-2}\right)$; and (d) cloud base radar reflectivity factor. The dotted line shows the $-17 \mathrm{dBZ}$ threshold used to decide the retrieval mode. The maximum drizzle water path along the cross-section is $0.2 \mathrm{~g} \mathrm{~m}^{-2}$.

In the retrieval process, we use 100 ensemble members; for each ensemble member, the state vector is initiated with a first guess perturbed with random noise with a given variance (specified in Table 2) so that Eqs. (19) and (20) can be evaluated. The large initial spread in ensemble members is required to allow the state space to be well explored and reduce the time to convergence. Note that no significant increase in accuracy was found when using more ensemble members.

Performance of the retrieval is judged against the accuracy and precision of the microphysical and the radiative properties of the retrieved cloud relative to the LES "truth". To assess the accuracy of the retrieval we use the bias between the truth and retrieved cloud properties, while to infer the precision we use the root-mean-square error (RMSE). Both column-mean properties, such as LWP and $\tau$, and vertically resolved properties, such as $W_{\mathrm{c}}$ and $r_{\mathrm{e}, \mathrm{c}}$, are investigated. In all our results we define cloud to be where $W_{\mathrm{c}}$ is greater than $0.01 \mathrm{~g} \mathrm{~m}^{-3}$ and drizzle to be where $W_{\mathrm{d}}$ is greater than $10^{-5} \mathrm{~g} \mathrm{~m}^{-3}$, similar to Zinner et al. (2010).

\subsection{Polluted case}

Retrieval performance for the polluted case is detailed using a $12.4 \mathrm{~km}$ cross-section example that corresponds to the largest cloud fraction in the snapshot domain. As shown in Fig. 3, the scene consists of a layer of broken stratocumulus with cloud base at $1.2 \mathrm{~km}$ and pockets of cumuli rising underneath, leading to a great variation in cloud bases detected by strong lidar returned signals. In general, Fig. 3 shows that the truth cloud water path (CWP) ranges between 1 and $100 \mathrm{~g} \mathrm{~m}^{-2}$, while the drizzle water path (DWP) is typically 4 orders smaller than the cloud water path in a given column. Although drizzle drops with non-negligible radar reflectivity 


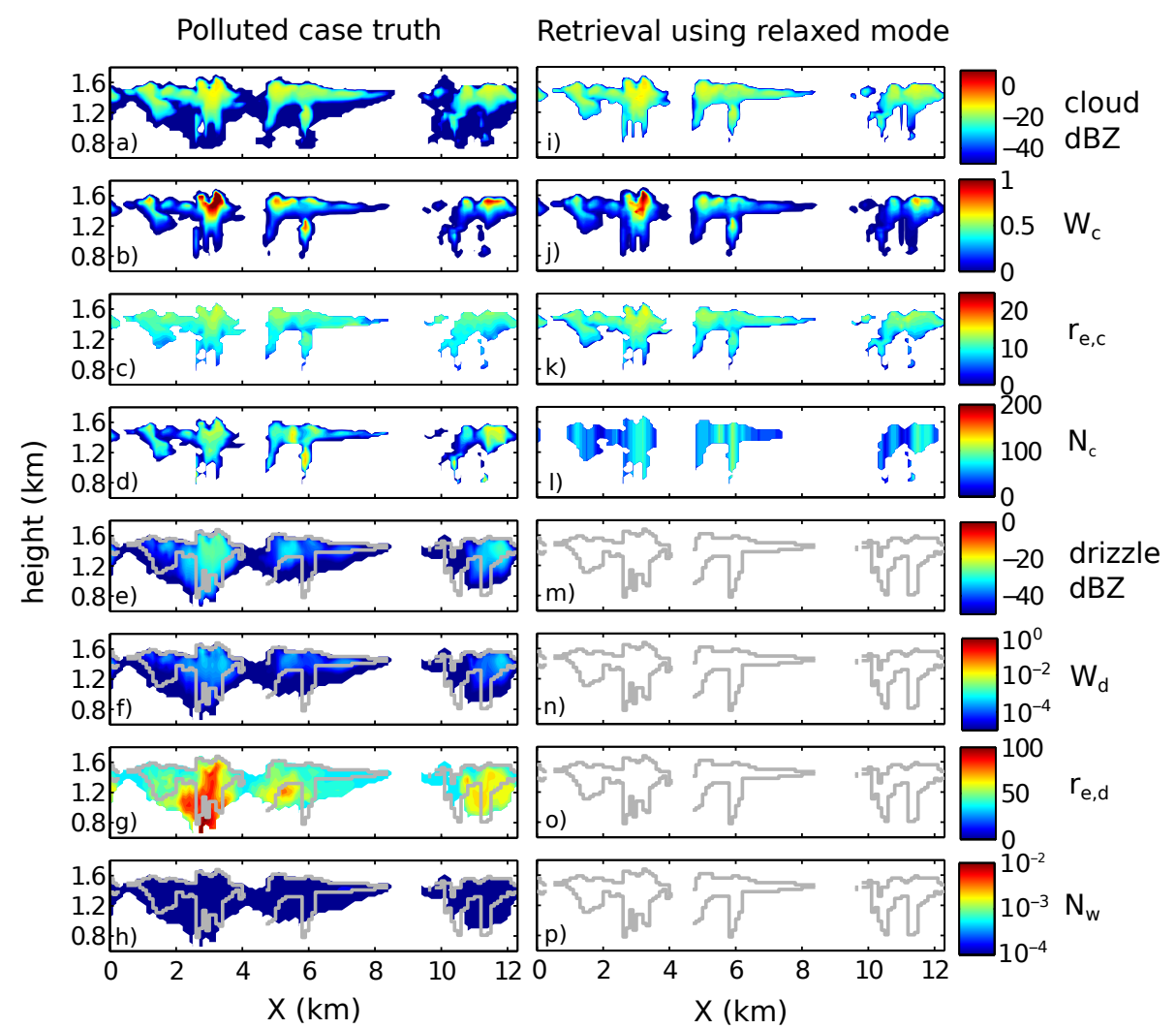

Figure 4. Truth (left panel) and retrieved (right panel) cloud- and drizzle-related properties for the polluted case. (a) Cloud radar reflectivity factor, (b) cloud water content $\left(\mathrm{g} \mathrm{m}^{-3}\right)$, (c) cloud effective radius $(\mu \mathrm{m})$ and $(\mathbf{d})$ cloud droplet number concentration $\left(\mathrm{cm}^{-3}\right)$. (e)-(h) are the same as (a)-(d) but for drizzle drops, except that (h) has units of $\mathrm{mm}^{-4}$. (i)-(p) are the same as (a)-(h) but for retrieved properties. The grey solid lines represent cloud base and cloud top.

are present at several locations in this cross-section (e.g. at $1.6 \mathrm{~km}$ altitude at $X=3 \mathrm{~km}$ in Fig. $4 \mathrm{e}$ ), Fig $3 \mathrm{~d}$ shows that cloud-base total reflectivity values are lower than $-17 \mathrm{dBZ}$, and the similarity between Figs. 3a and 4a shows that radar reflectivity is dominated by cloud droplets due to the low ratio of drizzle to cloud water. As a result, this scene was classified as non-drizzling, and drizzle properties were not retrieved. This example shows that a simple radar reflectivity threshold for binary drizzle classification may not be ideal, but retrieving this scene in relaxed mode (i.e. without any particular assumption in the cloud profile) allows radar reflectivity to be fully capitalised in determining cloud properties, as we demonstrate next.

Overall, the retrieval performs well in the polluted case; qualitatively, Fig. 4i-1 show that retrieved cloud properties are similar to the truth (Figs. 4a-d). To safely assume a monomodal DSD coupled with a height-invariant $N_{\mathrm{c}}$ requires the moments of the DSD to be correlated in a given column. Despite the fact that $N_{\mathrm{c}}$ (Fig. 4d) does vary somewhat with height, it is clear that the truth $Z_{\mathrm{c}}, W_{\mathrm{c}}$ and $r_{\mathrm{e}, \mathrm{c}}$ show significant correlation, which allows an accurate retrieval. No drizzle properties are retrieved (Fig. $4 \mathrm{~m}-\mathrm{p}$ ), but as discussed
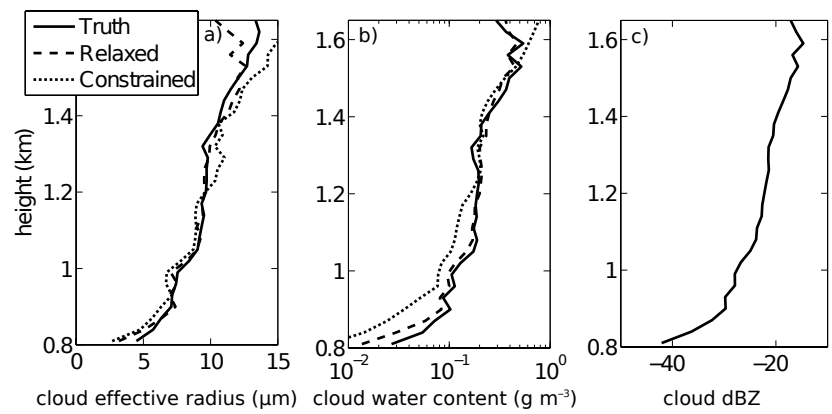

Figure 5. Cross-section mean profiles of cloud properties from the truth (solid line), retrievals in relaxed mode (dashed) and in constrained mode (dotted) for the polluted case: (a) cloud effective radius, (b) cloud water content and (c) cloud radar reflectivity factor.

in the previous paragraph, the concentration of drizzle in the truth is very low throughout the cross-section.

By considering the cross-section average profiles, Fig. 5 shows that the retrieved $W_{\mathrm{c}}$ and $r_{\mathrm{e}, \mathrm{c}}$ (dashed lines) are a good match to the truth and only deviate slightly at the cloud base and cloud top. From Fig. 4d we can see that at cloud base the true $N_{\mathrm{c}}$ is often smaller than the column average; the 

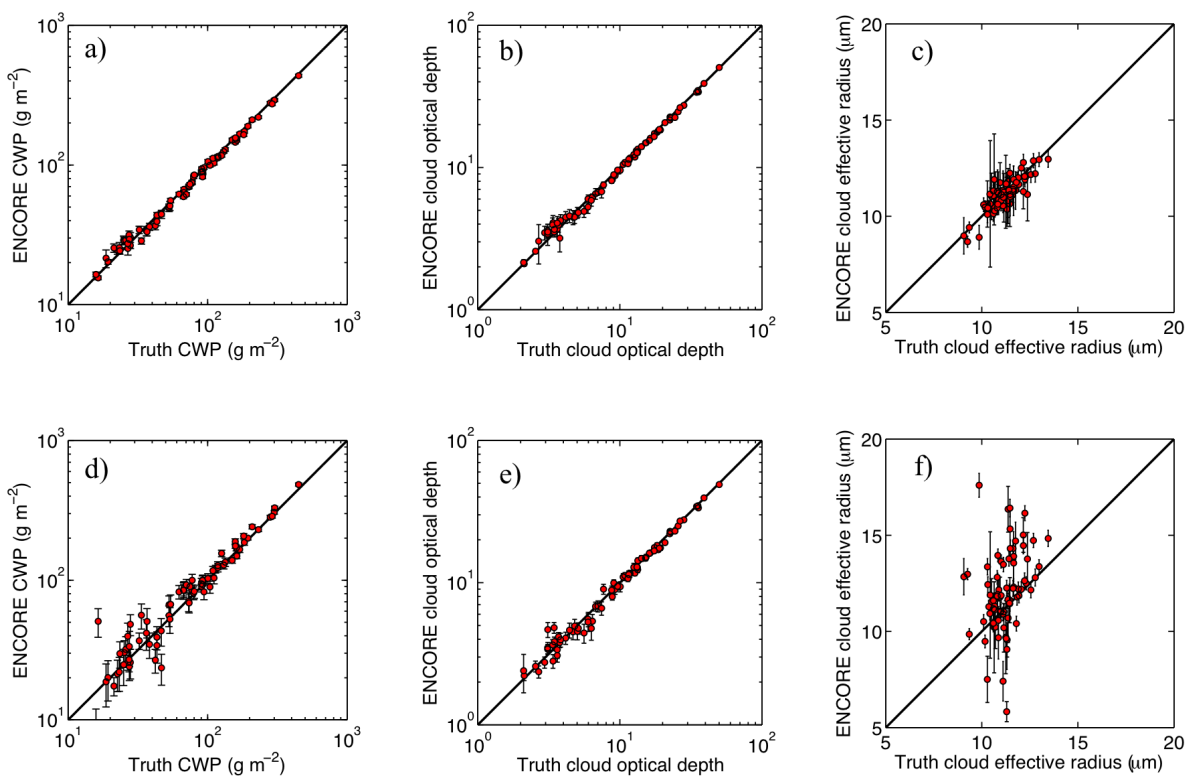

Figure 6. Comparison of retrieved column-averaged cloud properties with the truth for the polluted case using relaxed mode (top panel) and constrained mode (bottom panel). The error bars represent one standard deviation uncertainty. The black solid line represents the one-to-one line.

Table 3. Cross-section mean cloud properties* from the truth and the retrieval for the polluted and clean cases.

\begin{tabular}{|c|c|c|c|c|c|c|}
\hline & \multicolumn{2}{|c|}{$\begin{array}{l}\text { Cloud water } \\
\text { path }\left(\mathrm{g} \mathrm{m}^{-2}\right)\end{array}$} & \multicolumn{2}{|c|}{$\begin{array}{l}\text { Cloud effective } \\
\text { radius }(\mu \mathrm{m})\end{array}$} & \multicolumn{2}{|c|}{$\begin{array}{l}\text { Cloud optical } \\
\text { depth }\end{array}$} \\
\hline & Mean & RMSE & Mean & RMSE & Mean & RMSE \\
\hline \multicolumn{7}{|l|}{ Polluted case } \\
\hline Truth & 95 & - & 11.2 & - & 12.4 & - \\
\hline Relaxed mode & 92 & 6 & 11.2 & 0.5 & 12.1 & 0.5 \\
\hline Constrained mode & 101 & 14 & 12.1 & 3.1 & 12.3 & 0.7 \\
\hline \multicolumn{7}{|l|}{ Clean case } \\
\hline Truth & 93 & - & 17.3 & - & 7.5 & - \\
\hline Constrained mode & 98 & 31 & 16.8 & 3.6 & 8.1 & 1.8 \\
\hline
\end{tabular}

* Only cloudy columns with total optical depth greater than 2 are included in calculations.

number of cloud droplets typically increases in a cloud until the level of critical supersaturation is reached, which is normally above cloud base. Similarly, the true $N_{\mathrm{c}}$ at cloud top is smaller than the column average as entrainment reduces the droplet concentration. Consequently, the overestimated $N_{\mathrm{c}}$ at cloud base and cloud top corresponds to a larger $W_{\mathrm{c}}$ in Eq. (10) and thus a smaller $r_{\mathrm{e}, \mathrm{c}}$ retrieval as seen in Eq. (3) for a fixed $Z_{\mathrm{c}}$. However, these errors are small and generally only occur in the first $50 \mathrm{~m}$ above cloud base and $50 \mathrm{~m}$ below cloud top (Fig. 8d).

Scatter plots of cloud column properties (Fig. 6a-c) confirm the strong performance of the retrieval in relaxed mode with error bars showing one standard deviation uncertainty obtained from the ensemble spread. As effective radius is an intensive variable, we use an extinction-weighted average to define its column-mean value. Table 3 shows that both retrieved CWP and cloud optical depth have small bias $(<4 \%)$ and RMSE $(<7 \%)$. Similarly, column-mean effective radius has a small bias $(<1 \%)$ and RMSE $(<5 \%)$. Provided the instruments are calibrated correctly, these results suggest that cloud properties can be retrieved to a high accuracy in nondrizzling clouds.

We now consider the retrieval of the same cross-section using the constrained mode by assuming that all clouds meet the threshold for drizzle classification. Figure 5 shows that the cross-section mean cloud profiles are reasonable, but the errors are larger than those retrieved in relaxed mode. Without the constraint of radar reflectivity due to the assumptions 


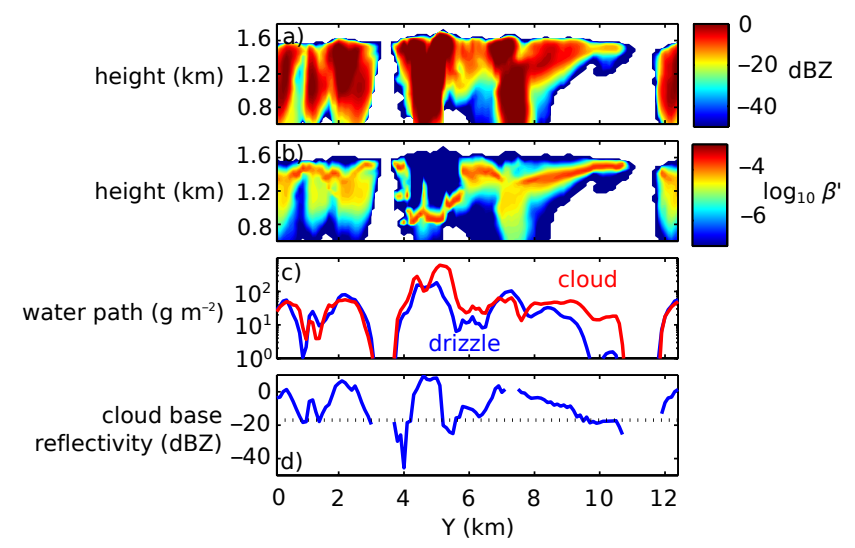

Figure 7. As Fig. 3, but for the clean case along the cross-section $X=8 \mathrm{~km}$ shown in Fig. $2 \mathrm{~b}$.

made in the constrained mode, $W_{\mathrm{c}}$ and $r_{\mathrm{e}, \mathrm{c}}$ tend to be underestimated near cloud base and overestimated at cloud top. This is because our simple model of condensational droplet growth does not include the effects of entrainment at cloud top or the faster condensational growth rate seen at cloud base. Despite this, these errors in the vertical profile tend to cancel such that the integrated cloud properties (e.g. CWP) are not far from the truth (Fig. 6d).

Figure $6 \mathrm{~d}-\mathrm{f}$ indicate that the uncertainty increases using the constrained mode compared to using the relaxed mode (Fig. 6a-c). In particular, the bias and RMSE in columnaveraged $r_{\mathrm{e}, \mathrm{c}}$ is around 8 and $26 \%$ respectively, which represents a 5-fold increase in uncertainty. Similarly, the bias and RMSE in CWP of 6 and $15 \%$ respectively are greater than the values found using the relaxed mode. In contrast, the uncertainty in $\tau_{\mathrm{c}}$ is similar to the relaxed mode; the bias and RMSE in $\tau_{\mathrm{c}}$ are $1 \%$ and $6 \%$ respectively. This shows that $\tau_{\mathrm{c}}$ is mainly constrained by the observations of zenith radiance that are common to both retrieval modes, while radar reflectivity adds considerable information to the retrieval of $r_{\mathrm{e}, \mathrm{c}}$, consistent with the finding in Fielding et al. (2014). Radar reflectivity is therefore of significant benefit to the retrieval of cloud properties in the relaxed mode and should be used wherever a monomodal DSD is likely.

\subsection{Clean case}

The second cross-section for evaluation was chosen from the clean case along $X=9 \mathrm{~km}$ in Fig. 2, containing one of the biggest surface rainfall cells. Figures 7 and 8 show that the cross-section consists of a thin layer of drizzling stratocumulus with cumulus clouds at $Y=4-6 \mathrm{~km}$ that contain $W_{\mathrm{c}}$ up to $2 \mathrm{~g} \mathrm{~m}^{-3}$. Unlike the previous polluted case, this cross-section has significant amounts of drizzle water path, which are comparable with the cloud water path (Fig. 7c). The cloud-base radar reflectivity is also generally greater than the $-17 \mathrm{dBZ}$ threshold, suggesting that retrieving cloud and drizzle prop- erties using the constrained mode is the most suitable approach for this cross-section.

We first consider the retrieved cloud properties - the upper panels in Fig. 8 show that both the $W_{\mathrm{c}}$ and $r_{\mathrm{e}, \mathrm{c}}$ are well retrieved throughout the cross-section in a qualitative sense, although evidently the detailed vertical structures shown in the truth are not fully captured by the retrievals due to the constraint of linearly increasing $W_{\mathrm{c}}$ with height. In particular, for sections where the truth $r_{\mathrm{e}, \mathrm{c}}$ decreases with height (e.g. $Y=6 \mathrm{~km}$ and $8-10 \mathrm{~km}$ ), the assumption made in the profile of $W_{\mathrm{c}}$ makes it impossible for retrieved $r_{\mathrm{e}, \mathrm{c}}$ to match the truth; in our model of condensational growth, $r_{\mathrm{e}, \mathrm{c}}$ will always increase with $W_{\mathrm{c}}$. Additionally, no retrievals are available at $Y=7 \mathrm{~km}$ as cloud base could not be determined due to the strong extinction of the lidar signal by the drizzle beneath cloud base. This problematic situation is associated with nonnegligible surface rainfall, which would also make zenith radiance measurements questionable in reality and thus would be an unfortunate limitation for our retrieval method.

The top panel of Fig. 9 shows the cross-section mean profiles of cloud properties to allow a more quantitative analysis of the retrieval. Two distinct cloud layers are apparent between $0.8-1.3$ and $1.3-1.6 \mathrm{~km}$; they are particularly visible in the profile of $r_{\mathrm{e}, \mathrm{c}}$ where the average $r_{\mathrm{e}, \mathrm{c}}$ decreases with height at around $1.3 \mathrm{~km}$. The first layer corresponds to cumulus only ( $Y=4-5 \mathrm{~km}$ in Fig. 8), while the second layer consists of stratocumulus and the upper layers of the cumulus. Despite these complex cloud conditions, the retrieved mean profiles of $W_{\mathrm{c}}$ and $r_{\mathrm{e}, \mathrm{c}}$ provide a close fit to the truth. Consequently, column-averaged $r_{\mathrm{e}, \mathrm{c}}$, CWP and $\tau$ are within 3, 6 and $8 \%$ of the truth respectively (Table 3 ). The RMSE in the retrieval is reasonable as shown by the spread in points in Fig. 10. Specifically, the RMSE in $r_{\mathrm{e}, \mathrm{c}}, \mathrm{CWP}$ and $\tau$ is 21 , 33 and $24 \%$ respectively. These errors are larger than the errors in the polluted case using the same constrained mode, which emphasises the challenge of retrieving cloud properties in drizzling conditions, but the overall performance remains satisfactory.

To analyse the retrieved drizzle properties, it is worth making a distinction between the drizzle below cloud base and the drizzle within cloud as they are retrieved in different ways. Below cloud base, the retrieved drizzle properties (red dots in Fig. 10d-f) show good agreement with the truth. This is to be expected as we have two observables, $Z$ and $\beta^{\prime}$, at each level to constrain the two free parameters in the monomodal DSD. Quantitatively, looking at Table 4, the mean retrieved DWP beneath cloud base has a small bias of $2 \%$, while $r_{\mathrm{e}, \mathrm{d}}$ and drizzle optical depth have biases of 13 and $9 \%$ respectively.

For drizzle within cloud, Fig. $8 \mathrm{e}-8 \mathrm{~h}$ and $8 \mathrm{~m}-8 \mathrm{p}$ show that drizzle properties are similar to the truth except in some parts at $Y=4-5 \mathrm{~km}$, coinciding with an area of rising cumulus underneath stratocumulus. Recall that two key assumptions were made during the retrieval of in-cloud drizzle properties. The first assumption is that $Z_{\mathrm{c}}$ can be reasonably retrieved 


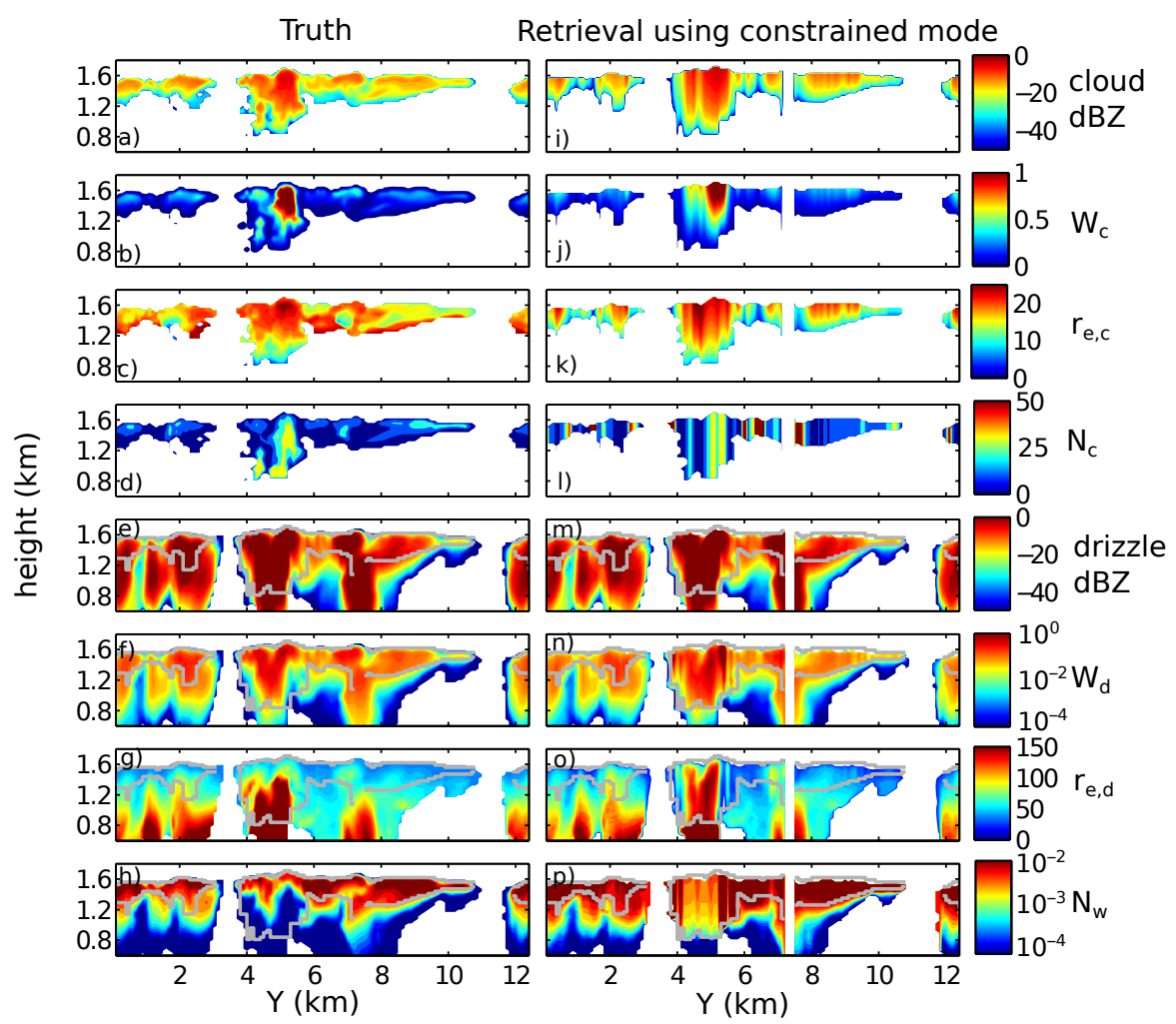

Figure 8. As Fig. 4, but for the clean case. Cloud and drizzle properties from the truth (left column) and retrievals using constrained mode (right column).
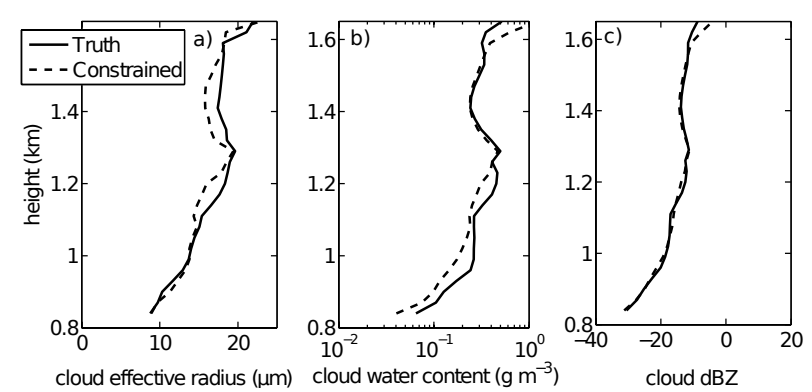

cloud effective radius $(\mu \mathrm{m})$
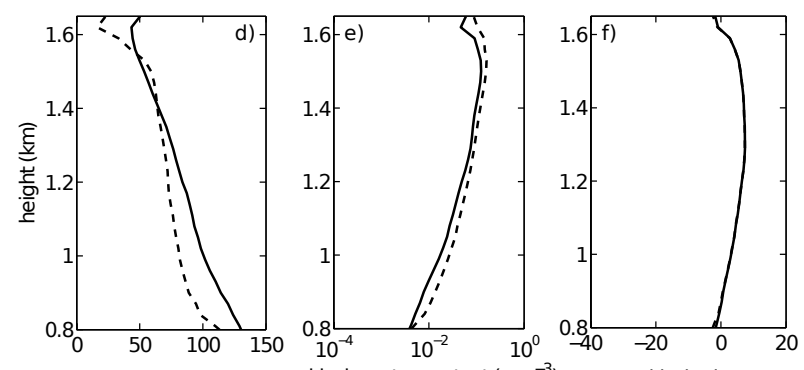

drizzle effective radius $(\mu \mathrm{m})$ drizzle water content $\left(\mathrm{g} \mathrm{m}^{-3}\right)$

drizzle dBZ

Figure 9. Cross-section mean profiles of cloud properties from the truth (solid line) and retrievals in constrained mode (dashed) for the clean case. (a)-(c) represent cloud effective radius, cloud water content and cloud radar reflectivity, respectively. (d)-(f) as (a)-(c) but for drizzle properties. so that the $Z_{\mathrm{d}}$ is given correctly by subtracting the $Z_{\mathrm{c}}$ from the observed reflectivity. We have found that this assumption works reasonably well as shown by the close match between the retrieved cloud reflectivity and the true cloud reflectivity in Fig. 8a, 8i and 9c. The second assumption is that $N_{\mathrm{w}}$ increases within cloud from cloud base, with its gradient equal to the gradient at cloud base. This assumption does not always hold; for example for the clouds at $Y=4-5 \mathrm{~km}$, where cumulus are present underneath the stratocumulus (Fig. 7b), the retrieved $N_{\mathrm{w}}$ in Fig. 8p increases too steeply with height in the lower layers compared to the truth in Fig. 8h, while the gradient of $N_{\mathrm{w}}$ is too shallow in the upper layers. For a given drizzle radar reflectivity, we can see from Eq. (11) that an overestimation of $N_{\mathrm{w}}$ will lead to an underestimation of $r_{0, v}$ and following from Eq. (7) an underestimation in $r_{\mathrm{e}, \mathrm{d}}$. Therefore, the overestimation of $N_{\mathrm{w}}$ in the lower layers between 0.8 and $1.3 \mathrm{~km}$ leads to an underestimation in the cross-section mean profile of $r_{\mathrm{e}, \mathrm{d}}$ (Fig. 9d).

Despite the difficulties in inferring in-cloud $N_{\mathrm{w}}$ for twolayer clouds, retrieved DWP and $r_{\mathrm{e}, \mathrm{d}}$ generally show agreement with the truth across the whole cross-section (blue dots in Fig. 10d-f), with correlation coefficients of 0.92 and 0.93 respectively. The mean bias in retrieved DWP and columnmean $r_{\mathrm{e}, \mathrm{d}}$ is -14 and $10 \%$ respectively as shown in Table 4. As the retrieval errors for the drizzle within cloud are comparable to the errors for the drizzle below cloud base, there is 

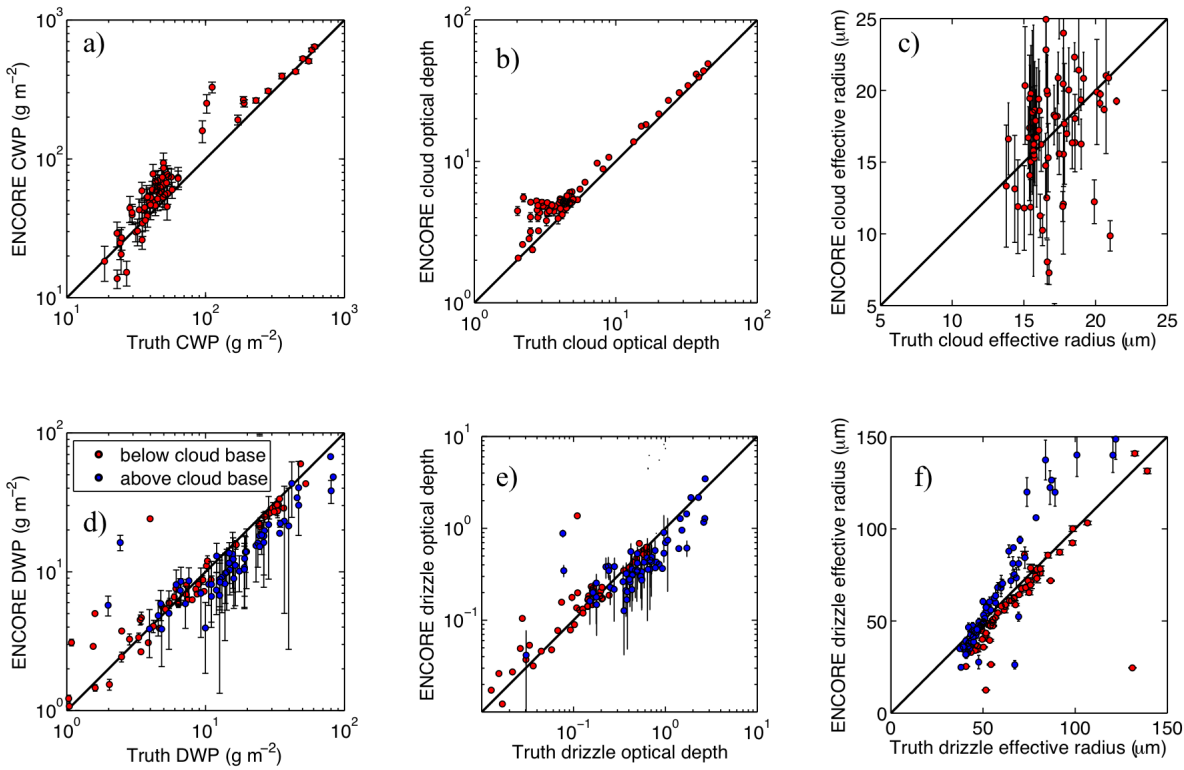

Figure 10. Comparison of retrieved column-averaged cloud properties (top panel) and drizzle properties (bottom panel) with the truth for the clean case, using constrained mode: (a) cloud water path, (b) cloud optical depth and (c) cloud effective radius; (d)-(f) as (a)-(c) but for drizzle properties below cloud base (red dots) and within clouds (blue dots). The error bars represent one standard deviation uncertainty. The black solid line represents the one-to-one line.

Table 4. Cross-section mean drizzle properties* from the truth and the retrieval for the clean case only.

\begin{tabular}{lcccccc}
\hline & \multicolumn{2}{c}{$\begin{array}{c}\text { Drizzle water } \\
\text { path }\left(\mathrm{g} \mathrm{m}^{-2}\right)\end{array}$} & \multicolumn{2}{c}{$\begin{array}{c}\text { Drizzle effective } \\
\text { radius }(\mu \mathrm{m})\end{array}$} & \multicolumn{2}{c}{$\begin{array}{c}\text { Drizzle optical } \\
\text { depth }\end{array}$} \\
& Mean & RMSE & Mean & RMSE & Mean & RMSE \\
\hline Below cloud base & & & & & & \\
\hline Truth & 6.09 & - & 82.4 & - & 0.114 & - \\
Constrained mode & 5.96 & 2.65 & 71.4 & 26.1 & 0.124 & 0.118 \\
\hline Within clouds & & & & & & \\
\hline Truth & 16.9 & - & 55.9 & - & 0.373 & - \\
Constrained mode & 14.5 & 13.11 & 61.6 & 15.0 & 0.268 & 0.283 \\
\hline
\end{tabular}

* Only cloudy columns with total optical depth greater than 2 are included in calculations.

much promise for the application of the method to reveal the detailed collocated covariance of cloud and drizzle properties anywhere within the cloud and how these properties relate to drizzle falling beneath the cloud.

\section{Evaluation using measurements from the MAGIC field campaign}

We now evaluate the retrieval method against measurements from the AMF MAGIC marine deployment. Potential cases were restricted to daytime with SZA smaller than $80^{\circ}$; when radar, lidar and shortwave spectrometers were all working properly; and when there was no cloud above the boundary layer. In particular, two cases were selected for intercompari- son to illustrate both non-drizzling and drizzling stratocumulus clouds. It is thought that nearly all marine clouds contain some drizzle drops (Fox and Illingworth, 1997); for example, using ARM data from the Azores, Kollias et al. (2011) detected drizzle in the Doppler spectra of marine stratus even when the radar reflectivity at cloud base was much lower than the $-17 \mathrm{dBZ}$ threshold used in this study. Similarly, during the MAGIC campaign, condensate was detected below cloud base in nearly all stratocumulus clouds (Zhou et al., 2015). However, as shown in Sect. 4.1, if drizzle concentration is sufficiently small, the relaxed mode of the retrieval that fully uses radar reflectivity information is favourable and will be used. 


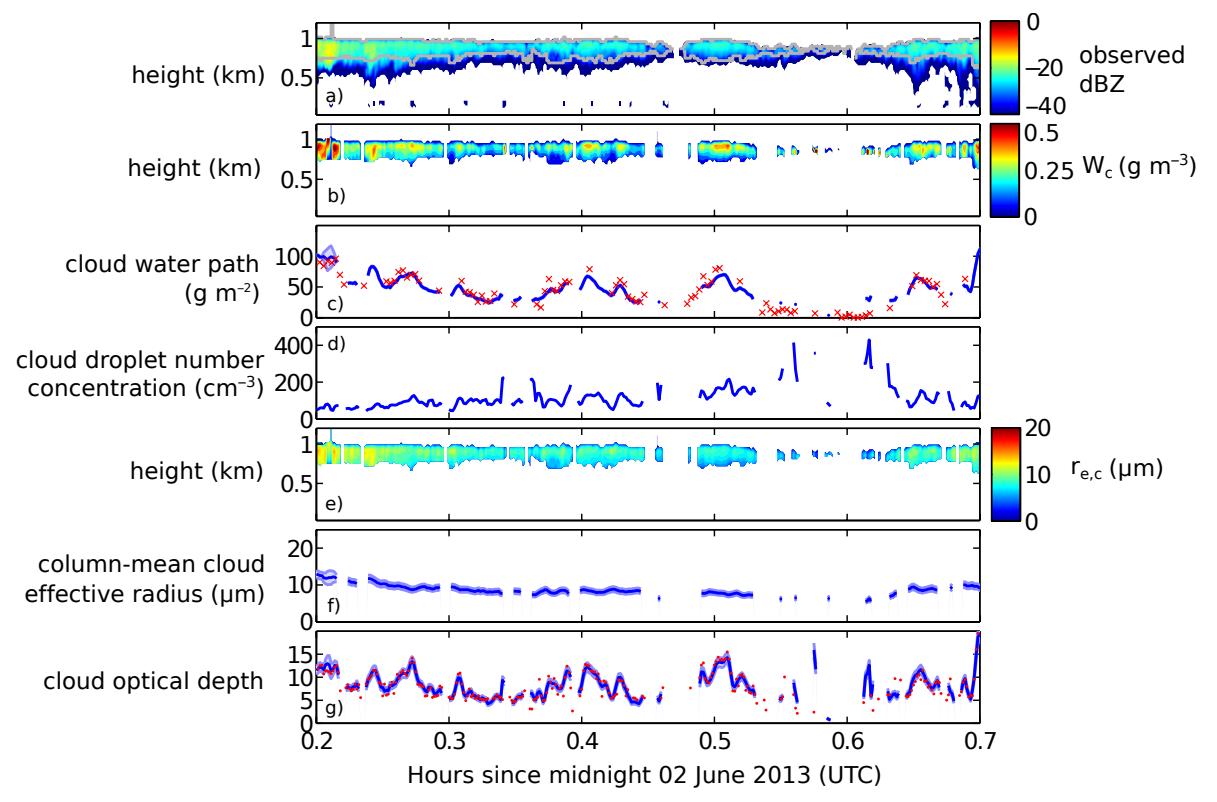

Figure 11. Retrieved cloud properties on 2 June 2013 during MAGIC in predominantly non-drizzling conditions. Panels show time series of (a) observed MWACR radar reflectivity factor, (b) retrieved cloud water content, (c) retrieved cloud water path from ENCORE (blue line) and the microwave radiometer (red crosses), (d) retrieved cloud droplet number concentration, (e) retrieved cloud effective radius, (f) retrieved column-averaged cloud effective radius and (g) cloud optical depth (blue line) and radiance only retrieval (red dots). The blue shading represents one standard deviation uncertainty in the retrieval. The grey solid lines represent cloud base and cloud top.

\subsection{Non-drizzling case: 2 June 2013}

The first case is a period of non-drizzling stratocumulus on 2 June 2013 at 00:12-00:42 UTC, after local noon. At the middle of the time period, the SZA was $36^{\circ}$ and the ship was positioned at $\left(25.2^{\circ} \mathrm{N}, 148.7^{\circ} \mathrm{W}\right)$. The observations correspond to Leg 11B when the Horizon Spirit was travelling towards Los Angeles. Figure 11a shows that observed radar reflectivity at cloud base is generally smaller than $-17 \mathrm{dBZ}$ and any virga below cloud base has very low reflectivity and small vertical extent. The cloud geometric thickness is fairly constant at around $200 \mathrm{~m}$, although the cloud thinned towards the middle of the time period.

During the time period, retrieved cloud water path ranged from $0-100 \mathrm{~g} \mathrm{~m}^{-2}$ (Fig. 11b), with a mean of $50 \mathrm{~g} \mathrm{~m}^{-2}$. Radar reflectivity and hence retrieved $W_{\mathrm{c}}$ increase with height in the cloud, suggesting that the cloud droplets have predominantly grown through vapour deposition. Columnmean $r_{\mathrm{e}, \mathrm{c}}$ is $12 \mu \mathrm{m}$ at the start of the period and decreases to $8 \mu \mathrm{m}$ in the middle period before rising to $10 \mu \mathrm{m}$ near the end; this range is consistent with in situ observations of marine non-drizzling stratocumulus (e.g. Wang et al., 2009). The $\tau_{\mathrm{c}}$ has a mean of 8 , but exhibits variability, peaking at 15 where smaller effective radii are observed for the cloud around 00:30 UTC.

The three-channel microwave radiometer retrieval (MWR) described in Sect. 2 uses independent observations to ENCORE and thus is particularly useful for evaluation. Qual-
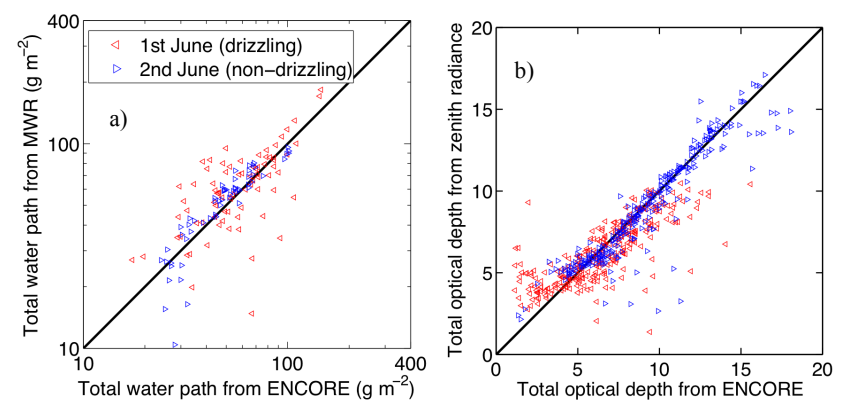

Figure 12. Comparison of ENCORE retrieval with (a) MWR-based liquid water path and (b) optical depth retrieved from zenith radiance for both the predominantly non-drizzling case shown in Fig. 11 (blue triangles) and for the drizzling case shown in Fig. 13 (red triangles). Black solid line represents the one-to-one line.

itatively, the MWR water path values are well correlated with the ENCORE retrieved water path (Fig. 11c). Quantitatively, using MWR as a reference, the mean bias in ENCORE is $-1 \mathrm{~g} \mathrm{~m}^{-2}$, which is less than $2 \%$ of the MWR mean. The scatter plot in Fig. 12a further supports this contention, showing that the majority of the points (blue triangles) are very close to the one-to-one line. The root-mean-squaredifference (RMSD) between the retrievals is $10 \mathrm{~g} \mathrm{~m}^{-2}$, which is $20 \%$ of the MWR mean and, assuming the retrievals are independent and unbiased, gives an upper bound to both retrievals' true uncertainty. 


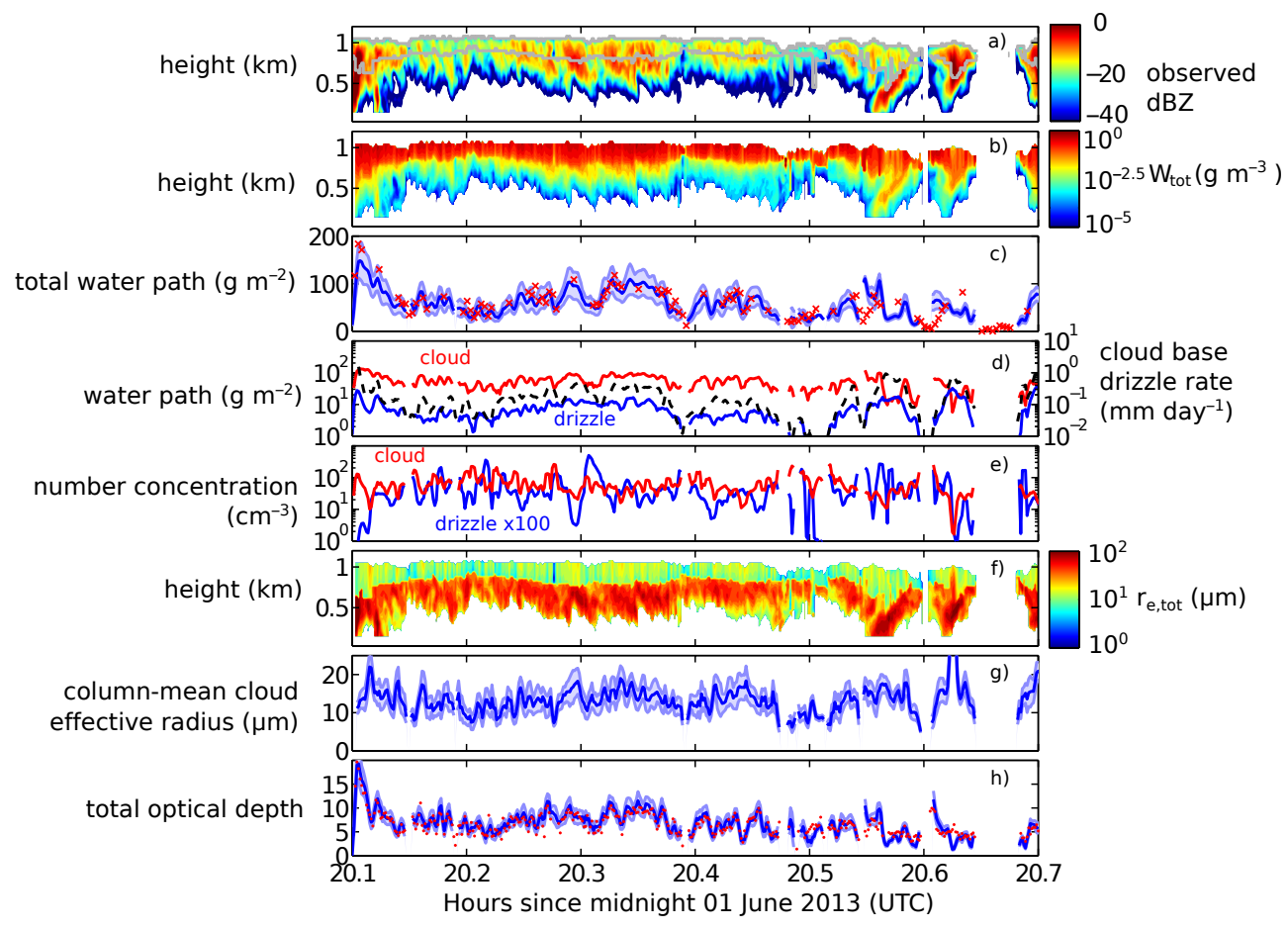

Figure 13. Retrieved cloud properties on 1 June 2013 during MAGIC in predominantly drizzling conditions. Panels show time series of (a) observed KAZR radar reflectivity factor, (b) retrieved total water content, (c) retrieved total water path from ENCORE (blue line) and the microwave radiometer (red crosses), (d) retrieved cloud (red) and drizzle (blue) liquid water path and cloud base drizzle rate (black dashed line), (e) retrieved cloud droplet number concentration (red) and retrieved drizzle droplet number concentration multiplied by 100 (blue), (f) retrieved total effective radius, (g) retrieved column-averaged cloud effective radius and (h) cloud optical depth (blue line) and radiance only retrieval (red dots). The blue shading represents one standard deviation uncertainty in the retrieval. The grey solid lines represent cloud base and cloud top.

As a consistency check, we compare the ENCORE cloud optical depth with the radiance-only retrieval described in Sect. 2. Both use the same zenith radiances and should show good agreement. As expected, Fig. $11 \mathrm{~g}$ shows a strong correlation between the two, and Fig. 12b highlights that most points are closely aligned with the one-to-one line. As a result, using radiance-only retrievals as a reference, the optical depth bias in ENCORE is 0.2, corresponding to $2 \%$ of the radiance-only mean. The RMSD of $1.2(15 \%)$ is comparable to the uncertainty in radiance-only retrievals (Chiu et al., 2012).

\subsection{Drizzling case: 1 June 2013}

The second case is a period of drizzling stratocumulus, $4 \mathrm{~h}$ prior to the first case just before local noon on 1 June 2013 at 20:06-20:42 UTC. In the middle of the time period, the SZA was $20^{\circ}$ and the ship was located at $\left(24.8^{\circ} \mathrm{N}, 149.7^{\circ} \mathrm{W}\right)$. As in the first case, the observations correspond to Leg 11B. Figure 13a shows that radar reflectivity decreases with height within cloud, which is indicative of drizzle sized drops growing as they descend within the cloud. Also, although negligible precipitation was recorded at the surface, virga can be seen to extend $500 \mathrm{~m}$ below cloud base. Both these factors point to a significant quantity of drizzle being present, and justify the retrieval algorithm operating in constrained mode.

\subsubsection{Cloud and drizzle properties in clouds}

We first consider the joint retrieval of cloud and drizzle above cloud base. Retrieved total water path is similar to the non-drizzling case with a mean of $60 \mathrm{~g} \mathrm{~m}^{-2}$ and a peak of $150 \mathrm{~g} \mathrm{~m}^{-2}$ at the start of the period. Figure 13d shows that the majority of condensate is classified as cloud; on average the cloud water path is 6 times the drizzle water path. There also appears to be a temporal correlation between the CWP and DWP as seen in other studies (O'Connor et al, 2005; Lebsock et al., 2013; Boutle et al., 2014). Additionally, $r_{\mathrm{e}, \mathrm{c}}$ is significantly larger than in the non-drizzling case, with an average of $13 \mu \mathrm{m}$, in accord with in situ observations of marine drizzling stratocumulus (e.g. Gerber, 1996; Twohy et al., 2005; Painemal and Zuidema, 2011). Despite similar CWP, cloud optical depth $\left(\tau_{\mathrm{c}}\right)$ is lower than the non-drizzling case with a mean of 6 due to the larger $r_{\mathrm{e}, \mathrm{c}}$.

As in the non-drizzling case, the retrieved total water path from ENCORE has a strong correlation with the MWR retrieval (Fig. 13c). However, since ENCORE is operating in constrained mode, the uncertainty in total water path shown 

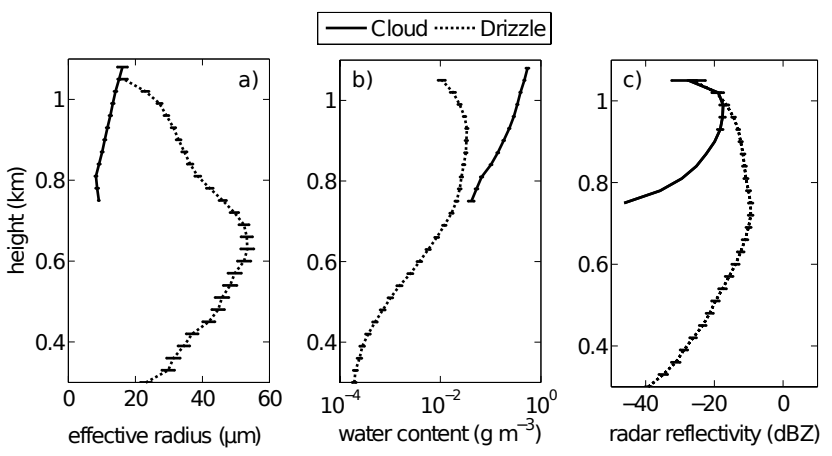

Figure 14. Mean cloud (solid lines) and drizzle (dotted lines) vertical profiles for the drizzling stratocumulus case shown in Fig. 13 during the time period 20:10-20:20 UTC: (a) effective radius $(\mu \mathrm{m})$, (b) water content $\left(\mathrm{g} \mathrm{m}^{-3}\right)$ and (c) forward-modelled radar reflectivity factor $(\mathrm{dBZ})$. The horizontal error bars show standard error at each height level.

by the blue shading is larger than in the non-drizzling case. This is the likely reason for the increased spread between MWR and ENCORE, as seen in Fig. 12a (red triangles). As a result, while the mean difference between the retrievals is less than $4 \mathrm{~g} \mathrm{~m}^{-2}$, the RMSD is $20 \mathrm{~g} \mathrm{~m}^{-2}$, which is twice the value seen in the non-drizzling case.

Similar to the non-drizzling case, the retrieved optical depth from ENCORE in Fig. 13h agrees well with the radiance-only retrieval and has a mean bias of 0.3. The uncertainty shown by the blue shading in Fig. 13h is larger than in the non-drizzling case, as radar reflectivity cannot be used directly to constrain the cloud properties. As a consequence, Fig. $12 \mathrm{~b}$ shows there is a slightly increased spread between the retrievals and a larger RMSD of 2.2.

In addition to column-integrated cloud and drizzle properties, the retrieval also allows us to take a more detailed look at the vertical structure of both cloud and drizzle, which is typically only possible from in situ measurements. Figure 14 shows the mean vertical profiles for cloud and drizzle between 20:10 and 20:20 UTC. Cloud water content increases from cloud base to cloud top with a mean of $0.7 \mathrm{~g} \mathrm{~m}^{-3}$ at $1000 \mathrm{~m}$, and $r_{\mathrm{e}, \mathrm{c}}$ increases from a mean cloud base of $800 \mathrm{~m}$ to a cloud top maximum of $1100 \mathrm{~m}$. Interestingly, $r_{\mathrm{e}, \mathrm{c}}$ near cloud top has a mean of $14 \mu \mathrm{m}$; this value has been suggested as a critical threshold for initialisation of drizzle (Rosenfeld et al., 2012). This size of cloud droplets is sufficient to allow the coalescence of droplets into small drizzle drops. $r_{\mathrm{e}, \mathrm{d}}$ can then be seen to increase as drizzle drops fall through the cloud and accrete cloud droplets. The maximum in $r_{\mathrm{e}, \mathrm{d}}$ is around $50 \mu \mathrm{m}$ at $200 \mathrm{~m}$ below cloud base, which shows that the self-collection of drizzle drops dominates evaporation in the cloud-free layers just below cloud base. Finally, Fig. 14c shows individual contributions of cloud and drizzle to the total reflectivity. In this case, drizzle reflectivity is greater than cloud reflectivity in all but the uppermost layers of the cloud. A more detailed analysis using a much greater sample size
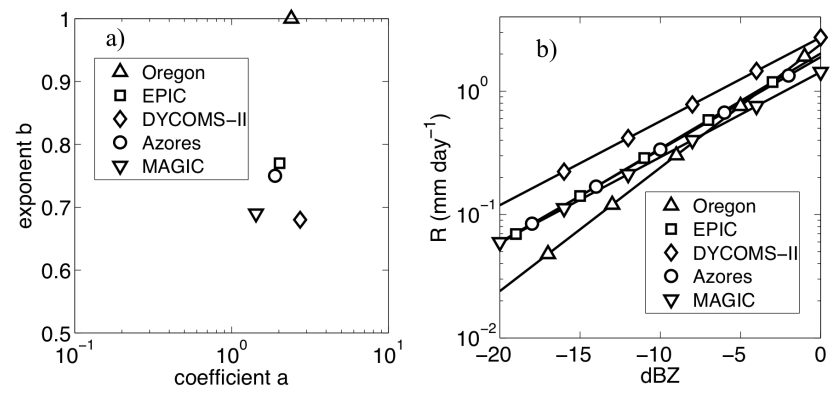

Figure 15. Fitted parameters (a) to a power law relationship (b) of the form $R=a Z^{b}$ in drizzling clouds, where $R$ is in units mm day ${ }^{-1}$ and $Z$ has units $\mathrm{mm}^{6} \mathrm{~m}^{-3}$. Observations include past measurements from marine stratus off the coast of Oregon, USA (Vali et al., 1998), the Eastern Pacific Investigation of Climate (EPIC; Comstock et al., 2004), the Dynamics and Chemistry of Marine Stratocumulus (DYCOMS-II; van Zanten et al., 2005), and marine stratocumulus at the Azores (Mann et al., 2014), and measurements from MAGIC in this paper.

is required to make robust conclusions, but this nevertheless shows the potential of the method to study the interactions between cloud and drizzle.

\subsubsection{Drizzle properties at cloud base}

While we have seen that drizzle drop size can reach a maximum several hundred metres below cloud base, drizzle rate typically peaks at cloud base, and its value is important in calculating the depletion of condensate from a cloud. The retrieved $r_{\mathrm{e}, \mathrm{d}}$ at cloud base across the whole time period varies between 20 and $80 \mu \mathrm{m}$ (Fig. 13f), while the mean cloud-base drizzle rate $\left(R_{\mathrm{cb}}\right.$; calculated using the models for drop terminal velocity in Beard, 1976) in Fig. 13d is around $0.01 \mathrm{~mm} \mathrm{day}^{-1}$ and peaks at $1 \mathrm{mmday}^{-1}$ at 20:38 UTC in the region of highest reflectivity $\sim 0 \mathrm{dBZ}$. The relationship between radar reflectivity and $R_{\mathrm{cb}}$ can be approximated by a power law, i.e. $R_{\mathrm{cb}}=a Z^{b}$, where $a$ and $b$ are fitted constants. By performing a linear regression with both $R_{\mathrm{cb}}\left(\mathrm{mm} \mathrm{day}^{-1}\right)$ and $Z\left(\mathrm{~mm}^{6} \mathrm{~m}^{-3}\right)$ in $\log$ space to predict $R_{\mathrm{cb}}$ given $Z$, we found values of 1.43 and 0.69 for $a$ and $b$ respectively.

Figure 15 shows our $Z-R_{\mathrm{cb}}$ relationship with those reported in the literature for other cases of marine boundarylayer clouds; these include coastal marine stratus in the Northeast Pacific using in situ aircraft measurements at cloud base (Vali et al., 1998), the Eastern Pacific Investigation of Climate experiment in the Southeast Pacific using shipborne radar measurements (EPIC; Comstock et al., 2004), Dynamics and Chemistry of Marine Stratocumulus in the southwest of Los Angeles using aircraft measurements (DYCOMS-II; vanZanten et al., 2005), and marine stratocumulus at the Azores using ground-based radar/lidar measurements (Mann et al., 2014; Wood et al., 2014). The $Z-R_{\text {cb }}$ relationships between MAGIC, EPIC and Azores cases are similar, while the coastal marine stratus in the Northeast Pacific from Vali et 
Table 5. Comparison of ENCORE and HSRL retrieved drizzle properties below cloud base.

\begin{tabular}{lcccc}
\hline & HSRL & ENCORE & Mean difference & RMSD \\
\hline Drizzle water content $\left(\mathrm{g} \mathrm{m}^{-3}\right)$ & $5.0 \times 10^{-3}$ & $4.5 \times 10^{-3}$ & $-5 \times 10^{-4}(10 \%)$ & $1.2 \times 10^{-3}(24 \%)$ \\
Drizzle effective radius $(\mu \mathrm{m})$ & 44.2 & 42.8 & $-1.4(3 \%)$ & $6.8(15 \%)$ \\
Drizzle extinction $\left(\mathrm{m}^{-1}\right)$ & $1.5 \times 10^{-4}$ & $1.4 \times 10^{-4}$ & $-1 \times 10^{-5}(7 \%)$ & $4.6 \times 10^{-5}(31 \%)$ \\
\hline
\end{tabular}

al. (1998) and DYCOMS-II respectively represent a lower and upper bound in drizzle rate at a given $Z$. Although $Z-$ $R_{\mathrm{cb}}$ relationships are convenient and useful in estimating rain rate when only radar reflectivity is available, caution should be exercised for more quantitative applications. Note that in addition to the drizzle microphysical properties, the fitted parameters are also influenced by many factors, including the method to obtain both radar reflectivity and rain rate at cloud base, the range of rain rates observed, and the fitting methods themselves (Steiner et al., 2004). Most saliently, a Z$R$ relationship is equivalent to creating a fixed relationship between drop size and drop concentration; where both values are known, as provided by our retrieval, it is best to report both to permit more conclusive comparisons. Routine measurements of drizzle properties, such as our retrievals, will be invaluable to make comparisons in cloud microphysical properties between regimes and will complement satellite observations greatly.

\subsubsection{Drizzle properties below cloud base}

This section focuses on drizzle properties below cloud base. As shown in Fig. 13b, most of the time the drizzle water content decreases below cloud base as the drizzle falls into sub-saturated air and begins to evaporate. However, in regions with heavier drizzle rate at cloud base, e.g. 20:38 UTC with a drizzle rate greater than $1 \mathrm{~mm}^{-1 a y}{ }^{-1}$, Figs. $13 \mathrm{f}$ and $14 \mathrm{a}$ shows that $r_{\mathrm{e}, \mathrm{d}}$ temporarily increases towards the ground due to collection of drops, before decreasing again when evaporation dominates.

For drizzle properties below cloud base, HSRL-based retrievals detailed in Sect. 2 are available for intercomparison. To restrict the sources of differences between the retrievals, the HSRL retrieval used the same assumed drop size distribution. Qualitatively, Fig. 16 shows that retrievals from ENCORE and HSRL are in good agreement for both $W_{\mathrm{d}}$ and $r_{\mathrm{e}, \mathrm{d}}$; correlation coefficients are 0.99 and 0.96 respectively. Quantitatively $W_{\mathrm{d}}$ has a mean difference of $10 \%$ and RMSE of $24 \%$, while $r_{\mathrm{e}, \mathrm{d}}$ has a mean difference of $3 \%$ and RMSE of $15 \%$ (Table 5).

The reasonable agreement between ENCORE and HSRLbased retrievals is to be expected as the retrievals share the same basic approach, but it is worth discussing potential sources of retrieval differences. Firstly, the HSRL retrieval uses a fixed lidar ratio of 15.4 determined from short segments of the data with relatively uniform drizzle using di-
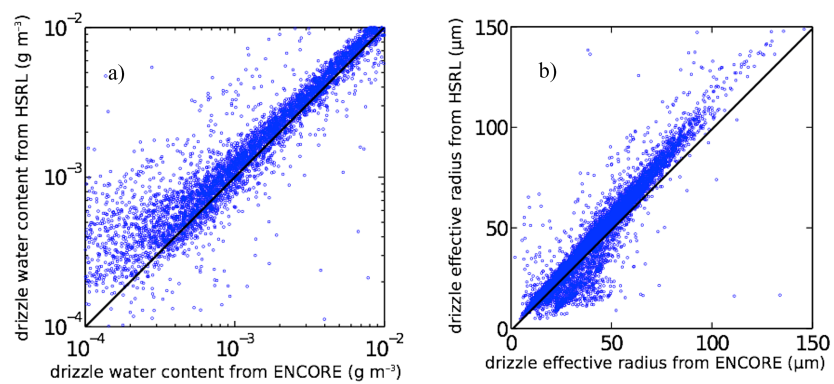

Figure 16. Comparison of ENCORE and HSRL retrieved drizzle properties below cloud base for the MAGIC drizzling case shown in Fig 13: (a) drizzle water content and (b) drizzle effective radius. The black solid line represents the one-to-one line.

rect measurements of the lidar extinction and a multiple scatter extinction correction (Eloranta, 1998). Secondly, unlike the HSRL retrieval, ENCORE does not account for multiple scattering in the lidar return. Multiple scattering affects the validity of Eq. (16), which assumes that only photons scattered in the exact backscatter direction will be received, and photons scattered in other directions will leave the FOV of the lidar. However, provided the sizes of the drizzle drops are much greater than the wavelength of the lidar, Babinet's principle states that one half of the lidar pulse is scattered into a narrow forward lobe (Van de Hulst, 1957; Hogan, 2006). When photons in the forward lobe travel further, they can be potentially scattered back to the receiver, which increases the apparent backscatter of subsequent gates (Hogan, 2008). To first order, the stronger apparent backscatter signal is interpreted as more drizzle drops, and would lead a retrieval that assumed single scattering to overestimate the drizzle extinction. The exact effect of neglecting multiple scattering in ENCORE is more complicated as any errors would be compounded in the forward modelling of attenuated backscatter at subsequent gates. However, as the mean difference in extinction between ENCORE and the HSRL retrieval is less than $10 \%$ (Table 5), we can assume that in this case multiple scattering is not a significant source of error.

\section{Summary and conclusions}

We have demonstrated a new method (ENCORE) to retrieve cloud and drizzle vertical profiles in drizzling boundary-layer clouds using observations of radar reflectivity, lidar attenu- 
ated backscatter and zenith radiances in a unified framework. Specifically, the vertical structure of both drizzle drop size and drizzle water content is retrieved within cloud, while simultaneously retrieving the vertical structure of cloud droplet size and cloud water content. Obtaining such information has not previously been possible for remote sensing and is even a challenge for in situ observations.

The capability of ENCORE has been tested using state-ofthe-art LES of cumulus under drizzling stratocumulus. These simulations show significant variability in cloud and drizzle structure, with a mean $r_{\mathrm{e}, \mathrm{c}}$ of $17 \mu \mathrm{m}$ and mean $r_{\mathrm{e}, \mathrm{d}}$ within cloud of $56 \mu \mathrm{m}$. Mean drizzle water path is $23 \mathrm{~g} \mathrm{~m}^{-2}$ and drizzle water content is often comparable to the cloud water content. In these complex conditions, cloud water path is retrieved with RMSE of $31 \mathrm{~g} \mathrm{~m}^{-2}$, while the bias is less than $5 \%$. Drizzle water path within clouds is similarly well retrieved, with a correlation coefficient compared to the truth of 0.92 , although multi-layer clouds provide an additional challenge.

The method also works well for non-drizzling cloud. In this case, evaluations with LES of non-drizzling stratocumulus show that the CWP, $r_{\mathrm{e}, \mathrm{c}}$ and $\tau_{\mathrm{c}}$ can all be retrieved to an extremely high accuracy. Provided all instruments are well calibrated it is shown that for the non-drizzling clouds uncertainty in cloud water path is $6 \mathrm{~g} \mathrm{~m}^{-2}$, column-mean cloud effective radius is $0.5 \mu \mathrm{m}$ and $\tau_{\mathrm{c}}$ is 0.5 .

Our retrieval method is also applied to MAGIC data collected from the climatically important stratocumulus decks in the Northeast Pacific during the first marine deployment of the ARM Mobile Facility. For the non-drizzling case, our retrievals show that the cloud droplet number concentration is of the order of $100 \mathrm{~cm}^{-3}$, while $r_{\mathrm{e}, \mathrm{c}}$ is about $10 \mu \mathrm{m}$ and $\tau_{\mathrm{c}}$ is between 5 and 15 , consistent with in situ and satellite observations reported in Painemal and Zuidema (2011) and King et al. (2013). Additionally, the mean retrieved LWP of $50 \mathrm{~g} \mathrm{~m}^{-2}$ agrees remarkably well with independent threechannel microwave radiometer retrievals with a RMSD of $10 \mathrm{~g} \mathrm{~m}^{-2}$.

For the drizzling case, the cloud water path remains of the order of $100 \mathrm{~g} \mathrm{~m}^{-2}$, associated with drizzle water path that is an order of magnitude smaller. Drizzle rate at cloud base peaks at $1 \mathrm{~mm} \mathrm{day}^{-1}$ and exhibits significant variability over time with a mean of $0.1 \mathrm{~mm} \mathrm{day}^{-1}$. In contrast to the nondrizzling case, the mean $r_{\mathrm{e}, \mathrm{c}}$ increases to $15 \mu \mathrm{m}$ but $\tau_{\mathrm{c}}$ reduces to 6.5. In these drizzling conditions the RMSD with the independent MWR LWP retrieval is $20 \mathrm{~g} \mathrm{~m}^{-2}$. Retrievals of $W_{\mathrm{d}}$ and $r_{\mathrm{e}, \mathrm{d}}$ below cloud base show good agreement with correlation coefficient of 0.99 and 0.96 respectively, with a semi-independent retrieval using HSRL extinction and radar backscatter.

To conclude, ENCORE provides retrievals of the microphysical properties of cloud, drizzle and their covariance at high spatial and temporal resolutions, much needed to advance our understanding of processes that control the microphysical and radiative properties of boundary layer clouds.
Potential applications are diverse, including investigations into precipitation initiation (e.g. Gerber, 1996; Rosenfeld et al., 2012; Chiu et al., 2014); aerosol effects on drizzle suppression (e.g. Ackerman et al., 2004; Lu et al., 2009; Wang et al., 2011; Mann et al., 2014) and the role of precipitation in cloud field organisation and variability (e.g. Wood and Hartmann, 2006; Xue et al., 2008; Feingold et al., 2010). Further, these retrievals are suited to help parameterise sub-grid variability of cloud and drizzle in general circulation models (e.g. Pawlowska and Brenguier, 2003; Ahlgrimm and Forbes, 2014) and cloud parameterisations based on probability density functions (e.g. Cheng and $\mathrm{Xu}, 2009$; Guo et al., 2011; Weber and Quaas, 2012; Boutle et al., 2014). Not least, these retrievals can help evaluate satellite observations (e.g. Leon et al., 2008; Lebsock et al., 2013), which are frequently used to evaluate the representation of current-day clouds in climate models (e.g. Klein et al., 2013).

Finally, the retrieval method presented here is a key step to the development of a 3-D retrieval cloud properties in drizzling conditions using scanning cloud radar, scanning lidar and zenith radiances. It is hoped that scanning lidar can provide information on the structure and variability of drizzle so that the method of Fielding et al. (2014) can be extended to the retrieval of drizzling clouds. The flexible ensemble framework used in both methods should allow the 3-D retrieval to be easily adapted using ideas from this study, and a similar evaluation of the method in 3-D with LES is foreseen.

Acknowledgements. ARM data are made available online through the US Department of Energy (DOE) as part of the Atmospheric Radiation Measurement Program at http://www.archive.arm.gov. This research was supported by the Office of Science (BER), DOE under grants DE-SC0006933, DE-SC0007233 and DESC0011666. Huiwen Xue is thanked for producing the large eddy simulations. The authors would like to thank Ernie Lewis and all those involved in making MAGIC happen. We acknowledge Horizon Lines and the Captain and crew of the Horizon Spirit for their and their hospitality, and the AMF2 technicians who performed the measurements. In particular we would like to thank David Troyan and Tami Toto for ship movement correction and Laurie Gregory, Richard Wagener and Cimel Electronique for their help with deploying the Cimel sun photometer on the ship.

Edited by: U. Wandinger

\section{References}

Ackerman, A. S., Kirkpatrick, M. P., Stevens, D. E., and Toon, O. B.: The impact of humidity above stratiform clouds on indirect aerosol climate forcing, Nature, 432, 1014-1017, 2004.

Ahlgrimm, M. and Forbes, R.: Improving the Representation of Low Clouds and Drizzle in the ECMWF Model Based on ARM Observations from the Azores, Mon. Weather Rev., 142, 668685, doi:10.1175/mwr-d-13-00153.1, 2014. 
Beard, K.: Terminal velocity and shape of cloud and precipitation drops aloft, J. Atmos. Sci., 33, 851-864, 1976.

Boutle, I. A., Abel, S. J., Hill, P. G., and Morcrette, C. J.: Spatial variability of liquid cloud and rain: observations and microphysical effects, Q. J. Roy. Meteor. Soc., 140, 583-594, doi:10.1002/qj.2140, 2014.

Cadeddu, M. P., Liljegren, J. C., and Turner, D. D.: The Atmospheric radiation measurement (ARM) program network of microwave radiometers: instrumentation, data, and retrievals, Atmos. Meas. Tech., 6, 2359-2372, doi:10.5194/amt-6-2359-2013, 2013

Cheng, A. and Xu, K.-M.: A PDF-based microphysics parameterization for simulation of drizzling boundary layer clouds, J. Atmos. Sci., 66, 2317-2334, 2009.

Chiu, J. C., Marshak, A., Huang, C.-H., Várnai, T., Hogan, R. J., Giles, D. M., Holben, B. N., O’Connor, E. J., Knyazikhin, Y., and Wiscombe, W. J.: Cloud droplet size and liquid water path retrievals from zenith radiance measurements: examples from the Atmospheric Radiation Measurement Program and the Aerosol Robotic Network, Atmos. Chem. Phys., 12, 1031310329, doi:10.5194/acp-12-10313-2012, 2012.

Chiu, J. C., Holmes, J. A., Hogan, R. J., and O'Connor, E. J.: The interdependence of continental warm cloud properties derived from unexploited solar background signals in groundbased lidar measurements, Atmos. Chem. Phys., 14, 8389-8401, doi:10.5194/acp-14-8389-2014, 2014.

Christensen, M. W., Stephens, G. L., and Lebsock, M. D.: Exposing biases in retrieved low cloud properties from CloudSat: a guide for evaluating observations and climate data, J. Geophys. Res.Atmos., 118, 12120-12131, doi:10.1002/2013jd020224, 2013.

Clothiaux, E., Mace, G., Ackerman, T., Kane, T., Spinhirne, J., and Scott, V.: An automated algorithm for detection of hydrometeor returns in micropulse lidar data, J. Atmos. Ocean. Tech., 15, 1035-1042, 1998.

Comstock, K. K., Wood, R., Yuter, S. E., and Bretherton, C. S.: Reflectivity and rain rate in and below drizzling stratocumulus, Q. J. Roy. Meteor. Soc., 130, 2891-2918, 2004.

Devenish, B. J., Bartello, P., Brenguier, J. L., Collins, L. R., Grabowski, W. W., IJzermans, R. H. A., Malinowski, S. P., Reeks, M. W., Vassilicos, J. C., Wang, L. P., and Warhaft, Z.: Droplet growth in warm turbulent clouds, Q. J. Roy. Meteor. Soc., 138, 1401-1429, doi:10.1002/Qj.1897, 2012.

Dong, X. Q. and Mace, G. G.: Profiles of low-level stratus cloud microphysics deduced from ground-based measurements, J. Atmos. Ocean. Tech., 20, 42-53, doi:10.1175/15200426(2003)020<0042:Pollsc>2.0.Co;2, 2003.

Donovan, D. and Lammeren, A.: Cloud effective particle size and water content profile retrievals using combined lidar and radar observations: 1 . Theory and examples, J. Geophys. Res.-Atmos., 106, 27425-27448, 2001.

Eloranta, E. W.: Practical model for the calculation of multiply scattered lidar returns, Appl. Optics, 37, 2464-2472, 1998.

Evans, K. F.: The spherical harmonics discrete ordinate method for three-dimensional atmospheric radiative transfer, J. Atmos. Sci., 55, 429-446, doi:10.1175/15200469(1998)055<0429:Tshdom>2.0.Co;2, 1998.

Feingold, G., Cotton, W., Stevens, B., and Frisch, A.: The relationship between drop in-cloud residence time and drizzle production in numerically simulated stratocumulus clouds, J. Atmos. Sci., 53, 1108-1122, 1996.

Feingold, G., Koren, I., Wang, H., Xue, H., and Brewer, W. A.: Precipitation-generated oscillations in open cellular cloud fields, Nature, 466, 849-852, 2010.

Fielding, M. D., Chiu, J. C., Hogan, R. J., and Feingold, G.: A novel ensemble method for retrieving properties of warm cloud in 3-D using ground-based scanning radar and zenith radiances, J. Geophys. Res.-Atmos., 119, 10912-10930, 2014.

Fox, N. I. and Illingworth, A. J.: The retrieval of stratocumulus cloud properties by ground-based cloud radar, J. Appl. Meteorol., 36, 485-492, doi:10.1175/15200450(1997)036<0485:troscp>2.0.co;2, 1997.

Frisch, A. S., Fairall, C. W., and Snider, J. B.: Measurement of stratus cloud and drizzle parameters in astex with a K-alpha-band doppler radar and a microwave radiometer, J. Atmos. Sci., 52, 2788-2799, doi:10.1175/15200469(1995)052<2788:Moscad>2.0.Co;2, 1995.

Frisch, A. S., Feingold, G., Fairall, C. W., Uttal, T., and Snider, J. B.: On cloud radar and microwave radiometer measurements of stratus cloud liquid water profiles, J. Geophys. Res.-Atmos., 103, 23195-23197, doi:10.1029/98jd01827, 1998.

Gerber, H.: Microphysics of marine stratocumulus clouds with two drizzle modes, J. Atmos. Sci., 53, 1649-1662, 1996.

Grecu, M. and Olson, W. S.: Precipitating snow retrievals from combined airborne cloud radar and millimeter-wave radiometer observations, J. Appl. Meteorol. Clim., 47, 1634-1650, doi:10.1175/2007jamc1728.1, 2008.

Guo, H., Golaz, J. C., and Donner, L.: Aerosol effects on stratocumulus water paths in a PDF-based parameterization, Geophys Res. Lett., 38, L17808, doi:10.1029/2011GL048611, 2011.

Hogan, R. J., Gaussiat, N., and Illingworth, A. J.: Stratocumulus liquid water content from dual-wavelength radar, J. Atmos. Ocean. Tech., 22, 1207-1218, doi:10.1175/Jtech1768.1, 2005.

Hogan, R. J.: Fast approximate calculation of multiply scattered lidar returns, Appl. Optics, 45, 5984-5992, 2006.

Hogan, R. J.: Fast lidar and radar multiple-scattering models. Part I: Small-angle scattering using the photon variance-covariance method, J. Atmos. Sci., 65, 3621-3635, 2008.

Holben, B. N., Eck, T. F., Slutsker, I., Tanre, D., Buis, J. P., Setzer, A., Vermote, E., Reagan, J. A., Kaufman, Y. J., Nakajima, T., Lavenu, F., Jankowiak, I., and Smirnov, A.: AERONET - A federated instrument network and data archive for aerosol characterization, Remote Sens. Environ., 66, 1-16, doi:10.1016/S00344257(98)00031-5, 1998.

Ichimura, I., Fujiwara, M., and Yanase, T.: The size distribution of cloud droplets measured in small maritime cumulus clouds, Meteorol. Soc. Japan J., 58, 403-415, 1980.

Iglesias, M. A., Law, K. J. H., and Stuart, A. M.: Ensemble Kalman methods for inverse problems, Inverse Probl., 29, 045001, doi:10.1088/0266-5611/29/4/045001, 2013.

Illingworth, A. J., Hogan, R. J., O'Connor, E. J., Bouniol, D., Brooks, M. E., Delanoe, J., Donovan, D. P., Eastment, J. D., Gaussiat, N., Goddard, J. W. F., Haeffelin, M., Baltink, H. K., Krasnov, O. A., Pelon, J., Piriou, J. M., Protat, A., Russchenberg, H. W. J., Seifert, A., Tompkins, A. M., van Zadelhoff, G. J., Vinit, F., Willen, U., Wilson, D. R., and Wrench, C. L.: Cloudnet -Continuous evaluation of cloud profiles in seven operational 
models using ground-based observations, B. Am. Meteorol. Soc., 88, 883-898, doi:10.1175/Bams-88-6-883, 2007.

King, N. J., Bower, K. N., Crosier, J., and Crawford, I.: Evaluating MODIS cloud retrievals with in situ observations from VOCALS-REx, Atmos. Chem. Phys., 13, 191-209, doi:10.5194/acp-13-191-2013, 2013.

Klein, S. A., Zhang, Y. Y., Zelinka, M. D., Pincus, R., Boyle, J., and Gleckler, P. J.: Are climate model simulations of clouds improving? An evaluation using the ISCCP simulator, J. Geophys. Res.-Atmos., 118, 1329-1342, doi:10.1002/Jgrd.50141, 2013.

Kollias, P., Szyrmer, W., Rémillard, J., and Luke, E.: Cloud radar Doppler spectra in drizzling stratiform clouds: 2. Observations and microphysical modeling of drizzle evolution, J. Geophys. Res.-Atmos., 116, D13203, doi:10.1029/2010JD015238, 2011.

Lebsock, M., Morrison H., and Gettelman A.: Microphysical implications of cloud-precipitation covariance derived from satellite remote sensing, J. Geophys. Res. Atmos., 118, 6521-6533, doi:10.1002/jgrd.50347, 2013

Lee, S., Kahn, B. H., and Teixeira, J.: Characterization of cloud liquid water content distributions from CloudSat, J. Geophys. Res.Atmos., 115, D20203, doi:10.1029/2009jd013272, 2010.

Leon, D., Wang C. Z., and Liu D.: Climatology of drizzle in marine boundary layer clouds based on 1 year of data from CloudSat and Cloud-Aerosol Lidar and Infrared Pathfinder Satellite Observations (CALIPSO), J. Geophys. Res., 113, D00A14, doi:10.1029/2008JD009835, 2008

Lewis, E. and Teixeira, J.: The MAGIC of Clouds, Eos, Transactions American Geophysical Union, accepted, 2015.

Liebe, H. J.: An updated model for millimeter wave propagation in moist air, Radio Sci., 20, 1069-1089, doi:10.1029/RS020i005p01069, 1985.

Liu, Y., Geerts, B., Miller, M., Daum, P., and McGraw, R.: Threshold radar reflectivity for drizzling clouds, Geophys. Res. Lett., 35, L03807, doi:10.1029/2007GL031201, 2008.

Lolli, S., Welton, E. J., and Campbell, J. R.: Evaluating light rain drop size estimates from multiwavelength micropulse lidar network profiling, J. Atmos. Ocean. Tech., 30, 2798-2807, doi:10.1175/Jtech-D-13-00062.1, 2013.

Lu, M. L., Sorooshian, A., Jonsson, H. H., Feingold, G., Flagan, R. C., and Seinfeld, J. H.: Marine stratocumulus aerosolcloud relationships in the MASE-II experiment: precipitation susceptibility in eastern Pacific marine stratocumulus, J. Geophys. Res.-Atmos., 114, D24203, doi:10.1029/2009JD012774, 2009.

Luke, E. P. and Kollias, P.: Separating cloud and drizzle radar moments during precipitation onset using Doppler spectra, J. Atmos. Ocean. Tech., 30, 1656-1671, 2013.

Mann, J. A. L., Chiu, J. C., Hogan, R. J., O'Connor, E. J., L'Ecuyer, T. S., Stein, T. H. M., and Jefferson, A.: Aerosol impacts on drizzle properties in warm clouds from ARM Mobile Facility maritime and continental deployments, J. Geophys. Res.Atmos., 119, 4136-4148, 2014.

Martin, W., Cairns, B., and Bal, G.: Adjoint methods for adjusting three-dimensional atmosphere and surface properties to fit multiangle/multi-pixel polarimetric measurements, J. Quant. Spectrosc. Ra., 144, 68-85, 2014.

Matrosov, S. Y., Uttal, T., and Hazen, D. A.: Evaluation of radar reflectivity-based estimates of water content in stratiform ma- rine clouds, J. Appl. Meteorol., 43, 405-419, doi:10.1175/15200450(2004)043<0405:Eorreo>2.0.Co;2, 2004.

Miles, N. L., Verlinde, J., and Clothiaux, E. E.: Cloud droplet size distributions in low-level stratiform clouds, J. Atmos. Sci., 57, 295-311, doi:10.1175/15200469(2000)057<0295:Cdsdil>2.0.Co;2, 2000.

Nakajima, T. Y., Suzuki, K., and Stephens, G. L.: Droplet growth in warm water clouds observed by the A-Train. Part I: Sensitivity analysis of the MODIS-derived cloud droplet sizes, J. Atmos. Sci., 67, 1884-1896, 2010.

Nicholls, S.: The dynamics of stratocumulus: aircraft observations and comparisons with a mixed layer model, Q. J. Roy. Meteor. Soc., 110, 783-820, 1984.

O'Connor, E. J., Illingworth, A. J., and Hogan, R. J.: A technique for autocalibration of cloud lidar, J. Atmos. Ocean. Tech., 21, 777-786, 2004.

O'Connor, E. J., Hogan, R. J., and Illingworth, A. J.: Retrieving stratocumulus drizzle parameters using Doppler radar and lidar, J. Appl. Meteorol., 44, 14-27, doi:10.1175/Jam-2181.1, 2005.

Painemal, D. and Zuidema, P.: Assessment of MODIS cloud effective radius and optical thickness retrievals over the Southeast Pacific with VOCALS-REx in situ measurements, J. Geophys. Res.-Atmos., 116, D24206, doi:10.1029/2011JD016155, 2011.

Pawlowska, H. and Brenguier, J. L.: An observational study of drizzle formation in stratocumulus clouds for general circulation model (GCM) parameterizations, J. Geophys. Res.-Atmos., 108, 8630, doi:10.1029/2002JD002679, 2003.

Platt, C., Young, S., Carswell, A., Pal, S., McCormick, M., Winker, D., DelGuasta, M., Stefanutti, L., Eberhard, W., and Hardesty, M.: The experimental cloud lidar pilot study (ECLIPS) for cloud-radiation research, B. Am. Meteorol. Soc., 75, 16351654, 1994.

Rémillard, J., Kollias, P., and Szyrmer, W.: Radar-radiometer retrievals of cloud number concentration and dispersion parameter in nondrizzling marine stratocumulus, Atmos. Meas. Tech., 6, 1817-1828, doi:10.5194/amt-6-1817-2013, 2013.

Rosenfeld, D., Wang, H., and Rasch, P. J.: The roles of cloud drop effective radius and LWP in determining rain properties in marine stratocumulus, Geophys. Res. Lett., 39, L13801, doi:10.1029/2012GL052028, 2012.

Squires, P.: The growth of cloud drops by condensation. I. General characteristics, Austral. J. Chem., 5, 59-86, 1952.

Steiner, M., Smith, J. A., and Uijlenhoet, R.: A microphysical interpretation of radar reflectivity-rain rate relationships, J. Atmos. Sci., 61, 1114-1131, 2004.

Stephens, G. L., Vane, D. G., Boain, R. J., Mace, G. G., Sassen, K., Wang, Z. E., Illingworth, A. J., O’Connor, E. J., Rossow, W. B., Durden, S. L., Miller, S. D., Austin, R. T., Benedetti, A., Mitrescu, C., and Team, C. S.: The cloudsat mission and the a-train - a new dimension of space-based observations of clouds and precipitation, B. Am. Meteorol. Soc., 83, 1771-1790, doi:10.1175/Bams-83-12-1771, 2002.

Stevens, B. and Lenschow, D. H.: Observations, experiments, and large eddy simulation, B. Am. Meteorol. Soc., 82, 283-294, 2001.

Teixeira, J., Cardoso, S., Bonazzola, M., Cole, J., DelGenio, A., DeMott, C., Franklin, C., Hannay, C., Jakob, C., and Jiao, Y.: Tropical and subtropical cloud transitions in weather and climate 
prediction models: the GCSS/WGNE Pacific Cross-Section Intercomparison (GPCI), J. Climate, 24, 5223-5256, 2011.

Twohy, C. H., Petters, M. D., Snider, J. R., Stevens, B., Tahnk, W., Wetzel, M., Russell, L., and Burnet, F.: Evaluation of the aerosol indirect effect in marine stratocumulus clouds: droplet number, size, liquid water path, and radiative impact, J. Geophys. Res.Atmos., 110, D08203, doi:10.1029/2004JD005116, 2005.

Twomey, S.: The nuclei of natural cloud formation part II: The supersaturation in natural clouds and the variation of cloud droplet concentration, Geofis. Pura Appl., 43, 243-249, 1959.

Ulbrich, C. W.: Natural variations in the analytical form of the raindrop size distribution, J. Clim. Appl. Meteorol., 22, 1764-1775, 1983.

Vali, G., Kelly, R. D., French, J., Haimov, S., Leon, D., McIntosh, R. E., and Pazmany, A.: Finescale structure and microphysics of coastal stratus, J. Atmos. Sci., 55, 3540-3564, 1998.

Van de Hulst, H. D.: Light Scattering by Small Particles, Wiley, New York, 1957.

vanZanten, M. C., Stevens, B., Vali, G., and Lenschow, D. H.: Observations of drizzle in nocturnal marine stratocumulus, J. Atmos. Sci., 62, 88-106, doi:10.1175/Jas-3355.1, 2005.

Wang, J. and Geerts, B.: Identifying drizzle within marine stratus with W-band radar reflectivity, Atmos. Res., 69, 1-27, 2003

Wang, J., Daum, P. H., Yum, S. S., Liu, Y. A., Senum, G. I., Lu, M. L., Seinfeld, J. H., and Jonsson, H.: Observations of marine stratocumulus microphysics and implications for processes controlling droplet spectra: results from the Marine Stratus/Stratocumulus Experiment, J. Geophys. Res.-Atmos., 114, D18210, doi:10.1029/2008jd011035, 2009.

Wang, M., Ghan, S., Ovchinnikov, M., Liu, X., Easter, R., Kassianov, E., Qian, Y., and Morrison, H.: Aerosol indirect effects in a multi-scale aerosol-climate model PNNL-MMF, Atmos. Chem. Phys., 11, 5431-5455, doi:10.5194/acp-11-5431-2011, 2011.

Weber, T. and Quaas, J.: Incorporating the subgrid-scale variability of clouds in the autoconversion parameterization using a PDF-scheme, J. Adv. Model. Earth Syst., 4, M11003, doi:10.1029/2012MS000156, 2012.

Westbrook, C. D., Hogan, R. J., O'Connor, E. J., and Illingworth, A. J.: Estimating drizzle drop size and precipitation rate using two-colour lidar measurements, Atmos. Meas. Tech., 3, 671-681, doi:10.5194/amt-3-671-2010, 2010.
Widener, K. and Johnson, K.: W-band ARM Cloud Radar (WACR) Handbook, The US Department of Energy, Washington DC, USA, 2006.

Widener, K., Bharadwaj, N., and Johnson, K.: Ka-band ARM Zenith Radar (KAZR) instrument handbook, DOE Office of Science Atmospheric Radiation Measurement (ARM) Program, US Department of Energy (DOE), Washington DC, USA, 2012.

Wood, R.: Parametrization of the effect of drizzle upon the droplet effective radius in stratocumulus clouds, Q. J. Roy. Meteor. Soc., 126, 3309-3324, 2000.

Wood, R.: Drizzle in stratiform boundary layer clouds. Part I: Vertical and horizontal structure, J. Atmos. Sci., 62, 3011-3033, 2005.

Wood, R.: Rate of loss of cloud droplets by coalescence in warm clouds, J. Geophys. Res.-Atmos., 111, D21205, doi:10.1029/2006jd007553, 2006.

Wood, R. and Hartmann, D. L.: Spatial variability of liquid water path in marine low cloud: the importance of mesoscale cellular convection, J. Climate, 19, 1748-1764, 2006.

Wood, R., Wyant, M., Bretherton, C. S., Rémillard, J., Kollias, P., Fletcher, J., Stemmler, J., deSzoeke, S., Yuter, S., and Miller, M.: clouds, Aerosol, and precipitation in the marine boundary layer: an ARM mobile facility deployment, B. Am. Meteorol. Soc., doi:10.1175/BAMS-D-13-00180.1, online first, 2014.

Xue, H., Feingold, G., and Stevens, B.: Aerosol effects on clouds, precipitation, and the organization of shallow cumulus convection, J. Atmos. Sci., 65, 392-406, 2008.

Zhang, Z. B., Ackerman, A. S., Feingold, G., Platnick, S., Pincus, R., and Xue, H. W.: Effects of cloud horizontal inhomogeneity and drizzle on remote sensing of cloud droplet effective radius: case studies based on large-eddy simulations, J. Geophys Res.-Atmos., 117, D19208, doi:10.1029/2012jd017655, 2012.

Zhou X., Kollias P., and Lewis E. R.: Clouds, Precipitation, and Marine Boundary Layer Structure during the MAGIC Field Campaign, J. Climate, 28, 2420-2442, doi:10.1175/JCLI-D-14$00320.1,2015$

Zinner, T., Wind, G., Platnick, S., and Ackerman, A. S.: Testing remote sensing on artificial observations: impact of drizzle and 3-D cloud structure on effective radius retrievals, Atmos. Chem. Phys., 10, 9535-9549, doi:10.5194/acp-10-9535-2010, 2010. 